\title{
Carvão ativado oriundo do mesocarpo do fruto da castanha de caju (Anacardium ccidentale) na remoção de corante em meio aquoso
}

Activated coal from the mesocarp of cashew nuts (Anacardium occidentale) in the removal of dye in water

Carbón activado del mesocarpio del anacardo (Anacardium ccidentale) en la eliminación de tinte en medios acuosos

\section{Resumo}

O despejo irregular de efluentes contendo corantes causa degradação do corpo hídrico. O objetivo desta pesquisa é confecção de carvão ativado através do mesocarpo da Castanha de Caju (Anacardium occidentale) para tratamento de água, por meio da adsorção, com a finalidade de remover o corante Verde Malaquita. Foi coletado $1 \mathrm{~kg}$ de biomassa residual de castanha de Caju, em uma Cooperativa no Munícipio de Ipixuna-PA, seguido de processo de ativação química com Hidróxido de Sódio $(\mathrm{NaOH})$. A caracterização da amostra foi realizada pelos métodos de espectroscopia de infravermelho com transformada de Fourier (FTIR), análise termogravimétrica (ATG), análise textural ( $\mathrm{S}_{B E T}$ ), Microscopia Eletrônica de Varredura (MEV/EDS). Quanto tratamento da água contendo o corante, foram realizados estudos para Equilíbrio e Cinética de adsorção. Nesse sentido, para equilíbrio, foram ajustados às isotermas de 
Freundlich e Langmuir, enquanto que para a cinética foram os modelos Pseudo-Primeira Ordem, Pseudo-Segunda Ordem e Difusão Intrapartícula. Os resultados de FTIR indicaram existência de grupos funcionais hidroxilas (OH) e carboxila $(-\mathrm{COOH})$. O MEV/EDS indicaram partículas sólidas empilhadas e aglomeradas, gerando agregados de morfologia irregular, revelando principalemente os elementos: Oxigênio $(\mathrm{O}=46,94 \%)$, Carbono $(\mathrm{C}=34,66 \%)$; Sódio $(\mathrm{Na}=16,13 \%)$. Quanto adsorção, para o equilíbrio ajustou-se o modelo de Langmuir $\left(\mathrm{R}^{2} a d j=0,8487 ; \mathrm{Q}_{\max }=573,83 \mathrm{mg} / \mathrm{g}\right.$ $\left.{ }^{-1}\right)$ e adsorção favorável com $\mathrm{R} L=0,0013$. Por outro lado, na Cinética ajustou-se, difusão intra-partícula $\left(\mathrm{R}^{2}\right.$ adj=0,9966; $\left.\mathrm{C}=69,13 \mathrm{mg} / \mathrm{g}^{-1}\right)$. Portanto, carvão ativado demonstrou eficácia na remoção do corante devido a influência de grupos orgânicos funcionais, que favorecem na interação de moléculas catiônicas.

Palavras-chave: Adsorção; Cinética; Isotermas.

\begin{abstract}
The irregular discharge of effluents containing dyes causes degradation of the water body. The objective of this research is to manufacture activated charcoal through the cashew nut mesocarp (Anacardium occidentale) for water treatment, by means of adsorption, in order to remove the dye Malachite Green. $1 \mathrm{~kg}$ of residual cashew nut biomass was collected in a cooperative in the municipality of Ipixuna-PA, followed by a chemical activation process with sodium hydroxide $(\mathrm{NaOH})$. The sample was characterized by Fourier transform infrared spectroscopy (FTIR), thermogravimetric analysis (ATG), textural analysis (SBET), Scanning Electron Microscopy (SEM / EDS). Regarding the treatment of the water containing the dye, studies were carried out for Equilibrium and adsorption kinetics. In this sense, for equilibrium, they were adjusted to the Freundlich and Langmuir isotherms, while for the kinetics they were the Pseudo-First Order, Pseudo-Second Order and Intraparticle Diffusion models. FTIR results indicated the existence of hydroxyl (OH) and carboxyl $(-\mathrm{COOH})$ functional groups. The SEM / EDS indicated solid particles stacked and agglomerated, generating aggregates of irregular morphology, mainly revealing the elements: Oxygen $(\mathrm{O}=46.94 \%)$, Carbon $(\mathrm{C}=34.66 \%)$; Sodium $(\mathrm{Na}=16.13 \%)$. As for adsorption, the Langmuir model was adjusted for equilibrium $\left(\mathrm{R}^{2}\right.$ adj $=0.8487 ; \mathrm{Q}_{\max }=$ $\left.573.83 \mathrm{mg} / \mathrm{g}^{-1}\right)$ and favorable adsorption with $\mathrm{R} L=0.0013$. On the other hand, in kinetics, intra-particle diffusion was adjusted $\left(\mathrm{R}^{2}\right.$ adj $\left.=0.9966 ; \mathrm{C}=69.13 \mathrm{mg} / \mathrm{g}^{-1}\right)$. Therefore, activated carbon has demonstrated effectiveness in removing the dye due to the influence of functional organic groups, which favor the interaction of cationic molecules.
\end{abstract}

Keywords: Adsorption; Kinetics; Isotherms.

\title{
Resumen
}

La descarga irregular de efluentes que contienen colorantes provoca la degradación de la masa de agua. El objetivo de esta investigación es la obtención de carbón activado a través del mesocarpio del anacardo (Anacardium occidentale) para el tratamiento del agua, mediante adsorción, con el fin de eliminar el tinte Verde Malaquita. Se recogió 1 kg de biomasa residual de marañón en una cooperativa del municipio de Ipixuna-PA, seguido de un proceso de activación química con hidróxido de sodio $(\mathrm{NaOH})$. La muestra se caracterizó por espectroscopía infrarroja por transformada de Fourier (FTIR), análisis termogravimétrico (ATG), análisis de textura (SBET), microscopía electrónica de barrido (SEM / EDS). En cuanto al tratamiento del agua que contiene el colorante, se realizaron estudios de equilibrio y cinética de adsorción. En este sentido, por equilibrio, se ajustaron a las isotermas de Freundlich y Langmuir, mientras que para la cinética fueron los modelos de Pseudo-Primer Orden, Pseudo-Segundo Orden y Difusión Intrapartícula. Los resultados de FTIR indicaron la existencia de grupos funcionales hidroxilo $(\mathrm{OH})$ y carboxilo (-COOH). El SEM / EDS indicó partículas sólidas apiladas y aglomeradas, generando agregados de morfología irregular, revelando principalmente los elementos: Oxígeno $(\mathrm{O}=46,94 \%)$, Carbono $(\mathrm{C}=34,66 \%)$; Sodio $(\mathrm{Na}=16,13 \%)$. En cuanto a la adsorción, el modelo de Langmuir se ajustó por equilibrio $\left(\mathrm{R}^{2} a d j=0,8487 ; \mathrm{Q}_{\max }=573,83 \mathrm{mg} / \mathrm{g}^{-1}\right)$ y adsorción favorable con $\mathrm{R} L=0,0013$. Por otro lado, en cinética, se ajustó la difusión intrapartícula $\left(\mathrm{R}^{2}\right.$ adj $\left.=0,9966 ; \mathrm{C}=69,13 \mathrm{mg} / \mathrm{g}^{-1}\right)$. Por tanto, el carbón activado ha demostrado eficacia en la eliminación del colorante debido a la influencia de grupos orgánicos funcionales, que favorecen la interacción de moléculas catiónicas.

Palabras clave: Adsorción; Cinética; Isotermas.

\section{Introdução}

A água é um recurso natural estratégico, devido aos seus serviços ecossistêmicos (regulação, provisão), compreendendo cerca de $70 \%$ do planeta Terra, desta porcentagem, apenas 3\% é considerada água doce superficial e, $98 \%$ é subterrânea. No homem, $70 \%$ do seu peso é composto por água e em algumas espécies animais, como por exemplo a Água Viva (Cnidaria), obtém em sua estrutura fisiológica 90\% de líquido (Guedes, 2017).

Nesse sentido, torna-se elemento indispensável à sobrevivência humana, com influência direta na sua saúde. Por estes motivos, é necessário que este recurso se encontre em quantidade e qualidade adequadas no ambiente. Ademais, a qualidade da água varia em função de seu uso, classificados em: Consuntivo a partir do abastecimento doméstico e industrial e uso consuntivo 
por meio de navegação e recreação (Beltrame, lhamby\& Beltrame, 2016).

Estes usos, em especial o caráter consuntivo, trazem como subproduto efluentes líquidos que, normalmente, são subdivididos em dois tipos quanto à sua gênese: Efluentes domésticos provenientes das residências, hotéis e industriais oriundos dos mais diversificados processos de industrialização. Dentre esses meios, as indústrias têxteis consomem água em grandes quantidades durante seus processos, especialmente nas etapas de lavagem e tingimento e, consequentemente, geram efluentes com grande carga de comp orgânicos e inorgânicos (Pizato, et al., 2017).

Nessas perspectivas, o despejo desses efluentes de forma inadequada em corpos hídricos, traz consequências severas ao ecossistema aquático, uma vez que o corante orgânicos contido neste, pode modificar parâmetros químicos e físicos, como Cor (uH) e turbidez (UT), ainda que em pequenas quantidades, tornando dificultoso a capacidade de penetração dos raios solares e impossibilita a atividade fotossintética do corpo hídrico e, dessa forma, favorece a alteração na dinâmica populacional dos seres vivos deste ecossistema (Patias, et al., 2015).

Desse modo, uma das medidas de remediação dos problemas envolvendo a qualidade da água é por meio do processo de adsorção, sendo este um dos métodos mais utilizados nas últimas décadas, como um grande promissor dentre as técnicas de regulação de substâncias poluentes no meio hídrico (Coelho, Rozário, 2019).

A adsorção é conceituada como uma operação unitária de transferência de massa, voltada a estudar a capacidade que certos sólidos possuem em concentrar na sua superfície determinadas substâncias existentes em um fluido, de forma que possibilita a separação de poluentes presentes nesses fluidos. Isto ocorre devido a forças de atração que fazem com que as moléculas de materiais em suspensão (adsorvato) fiquem retidas na superfície do sólido (adsorvente), tornando a adsorção um dos processos mais eficientes de pós-tratamento (Vasques, et al., 2011).

No entanto, para se obter eficiência neste processo é essencial a escolha de um adsorvente que obtenha elevado potencial de remoção, disponibilidade e menor custo. Este processo necessita de diversos fatores como, área superficial, tamanho do poro, densidade, grupos funcionais presentes na superfície e hidrofobicidade do solido. Além disso, existem variados tipos de adsorventes utilizados, seja eles de origem inorgânica (argilas, zeólitas), ou orgânica (biomassa, carvão ativado) (Oliveira; Silva, Viana, 2013).

Dentro disso, o carvão ativado é produzido a partir de materiais com alto teor de carbono, poroso e microcristalino, como casca de coco, hulha, bambu, grão de café, quitosana, madeira, castanha de caju (Anacardium occidentale) e lignina. Materiais esses, considerados alternativos e residuais de outros processos, que trazem como principal benefício, o baixo custo (cid, et al., 2016).

Seguindo tais preceitos, o caju (Anacardium occidentale), fruto predominante no nordeste do Brasil, é constituído basicamente de um pseudofruto (pedúnculo) e o fruto, propriamente dito, que é composto por uma amêndoa envolvida pelo pericarpo, ou casca da castanha de caju, dividida em endocarpo, mesocarpo esponjoso e epicarpo. Em sua composição apresenta elevado teor de carbono (49,53\%), característica que viabiliza o seu uso para a produção do carvão ativado (Mazzetto, et al., 2009; Coelho, 2014).

Portanto, o aumento da degradação dos corpos hídricos, devido ao lançamento inadequado de efluentes industriais, causa danos severos nos meios bióticos e abióticos. Com isso, o objetivo desta pesquisa é produzir e avaliar o carvão ativado de biomassa residual do mesocarpo da Castanha de Caju (Anacardium occidentale) para aplicação no processo de adsorção de corante em meio aquoso. 


\section{Fundamento Teórico}

\subsection{Efluentes Industriais com corantes}

O desenvolvimento tecnológico e expansão das atividades industriais, atrelados ao crescimento populacional, trouxe consigo consequências severas ao meio ambiente, especificamente ao meio aquático. Dessa maneira, fato preocupante é o despejo de efluentes nos corpos hídricos, que afetam o meio ambiente através da poluição química de natureza orgânica ou inorgânica (Pott, Estrela, 2017).

Em decorrência disso, conceitua-se poluição hídrica, como alterações físicas, químicas ou biológicas de um manancial superficial ou subterrâneo, que promova modificação no ciclo hidrológico natural e cause interferência na qualidade da água, conforme o seu uso preponderante. Grande parte dos poluentes, encontrados em efluentes com corantes, são substâncias químicas que, ao serem descartados sem tratamento em corpos hídricos, são capazes de degradar o meio aquático (RAMOS et al., 2020). Nos processos industriais é utilizado carga hídrica elevada, gerando grandes volumes de efluentes variadas composições. O setor industrial utiliza água de forma consuntiva, ou seja, retiram do manancial para sua eventual finalidade, durante as etapas de processamento, e não repõem para o ambiente na mesma quantidade e/ou qualidade com que este recurso foi captado (Crini, Lichtfouse, 2019).

Diversas indústrias utilizam em seus processos produtivos corantes sintéticos, como por exemplo têxteis, alimentos, couro, cosméticos, papel, dentre outros. Todavia, cerca de dois terços de todo corante produzido encontram-se disponíveis para a indústria têxtil, onde sua utilização é extensiva (Gupta, et al., 2016).

O descarte inadequado desses efluentes tem causado degradação ambiental devido ao seu potencial de contaminação nos corpos hídricos. Estes possuem em sua composição elementos químicos nocivos ao meio, os quais modificam parâmetros físicos como temperatura; Sabor e odor; Cor; Turbidez; Condutividade Elétrica, e químicos nos índices de Oxigênio Dissolvido (OD); Demanda Bioquímica de Oxigênio (DBO); Demanda Química de Oxigênio (DQO); potencial hidrogeniônico(pH) dos mananciais onde são descartados (Silva; Junior \& Lobato, 2020). Devido a isto, estes são os contaminantes mais preocupantes em efluentes têxteis, pois, suas características não-biodegradáveis, dificultam sua remoção do meio por tratamentos convencionais (Tkaczyk, Mitrowska \& Posyniak, 2020).

Além disso, as partículas de corantes resultam em elevadas concentrações de sólidos suspensos, que dificulta na entrada de luz, consequentemente atrapalha no processo de fotossíntese, fator este imprescindível na dinâmica e regulagem do ecossistema aquático, por influenciar nos níveis de OD (Liang, et al., 2018).

Quanto à classificação de corantes, podem ser de acordo com a estrutura, aplicação e cor (Quadro 1).

Quadro 1 - classificação dos corantes quanto a sua definição e natureza química.

\begin{tabular}{|c|c|}
\hline CLASSE/ CORANTES & DEFINIÇÃO \\
\hline Tina & $\begin{array}{c}\text { São divididos em dois grupos: Antraquinonicos e indigoides. Além disso, são insolúveis em } \\
\text { água, sua solublização acontece por redução alcalina }\end{array}$ \\
\hline Reativos & Possuem grupo cromoforo (Capacidade de absorver energia) e reativos. São solúveis em água \\
\hline Dispersos ou plastossoluveis & Natureza Iônica, insolúveis em água com afinidade com fibras hidrofílicas (Acetato de celulose) \\
\hline Diretos & Caráter aniônico, possui afinidade com celulose \\
\hline Ácidos & Aniôcos, altamente solúveis em água \\
\hline Básicos (Catiônicos) & $\begin{array}{c}\text { Caráter básico, solúveis em água, com soluções coloridas catiônica devido, o agrupamento } \\
\text { Amino (NH2) }\end{array}$ \\
\hline Sulfurosos & Insolúveis em água, macromoleculares com pontes dissulfidicas (-S-S-) \\
\hline Naturais & A partir de substâncias animais ou vegetais, com baixo processo químico \\
\hline
\end{tabular}

Fonte: Autores (2021). 
Do ponto de vista ambiental, na indústria têxtil, a etapa de tingimento é a mais preocupante pela quantidade de produtos químicos empregados de maneira especial, pelas macromoléculas complexas dos corantes utilizados que não se fixaram na fibra do tecido e são descartados. Estima-se que mais $70 \%$ da carga orgânica de corantes que entram no meio ambiente é advinda dos efluentes industriais têxteis (Gomes, 2015).

Além segmento utilizar esse produto em larga escala, o setor pouco investe em medidas de controle e tratamento. Ainda em vista disso, não se tem um método universalmente para remediação desses enfluentes contendo corantes devido à alta complexidade desses compostos, variedade e concentração, e características como alta solubilidade e nocividade (Bankole, et al., 2018).

\subsection{Adsorção}

Operação de transferência de massa por difusão, a qual estuda a habilidade de certos sólidos em concentrar na sua superfície determinadas substâncias existentes em fluidos líquidos. é um processo de alta seletividade, no âmbito molecular, que tem se destacado, principalmente por se demonstrar eficaz na remoção de substâncias contaminantes, como por exemplo corantes, que possuem alto potencial de degradação em corpos hídricos (Müller, et al., 2019).

Este processo ocorre em quatro fases: (a) Movimentação por difusão; (b) Transporte na solução de alimentação; (c) Superfície e nos poros; (d) Adsorção. Neste contexto, a capacidade de adsorção de um contaminante em um fluido pode ser quantificada através das isotermas de adsorção (Metcalf, Eddy, 2016).

Pode ser classificada de duas formas: Adsorção Física (Fisiossorção) e Adsorção Química (Quimiossorção). A fisiossorção trata-se da ligação do adsorvato à superfície do adsorvente através de uma interação relativamente fraca atribuída às forças de Van der Waalls. Por outro lado, a Quimiossorção corresponde à troca de íons entre as moléculas do adsorvato e a superfície do adsorvente, consequentemente a formação de uma nova ligação química (Kawahigashi, et al., 2014).

Além disso, diversos fatores influenciam diretamente no processo de devido este ser a combinação de forças de natureza química e física. Dentre estes, destacam-se, por exemplo, as características do adsorvente (área superficial, tamanho dos poros), haja vista que a capacidade de retenção do adsorvato no adsorvente é integralmente proporcional a sua superfície (Oliveira, et al., 2018).

\subsection{Equilíbrio de adsorção}

Trata-se do processo em que o número de moléculas que chegam à superfície do adsorvente é igual ao quantitativo de moléculas que deixam a superfície do sólido em um fluido. Ao explorar a capacidade de adsorção, o estudo de equilíbrio faz-se fundamental, pois é utilizado para descrever o processo graficamente, através das isotermas de adsorção (Brandão.,2010; Bezerra, et al., 2019).

As isotermas podem ser determinadas de acordo com as características físicas do material (adsorvente), como por exemplo, porosidade e área superficial. A partir disso, foi criado a classificação, baseada em quatro modelos de isotermas (C; L; H; S) que buscam descrever o processo de forma mais representativa possível, usados principalmente para soluções aquosas (Figura 1), e evidenciar suas características (Giles, et al.,1974; Fernandes, et al., 2019). 
Figura 1 - Classificação das isotermas.

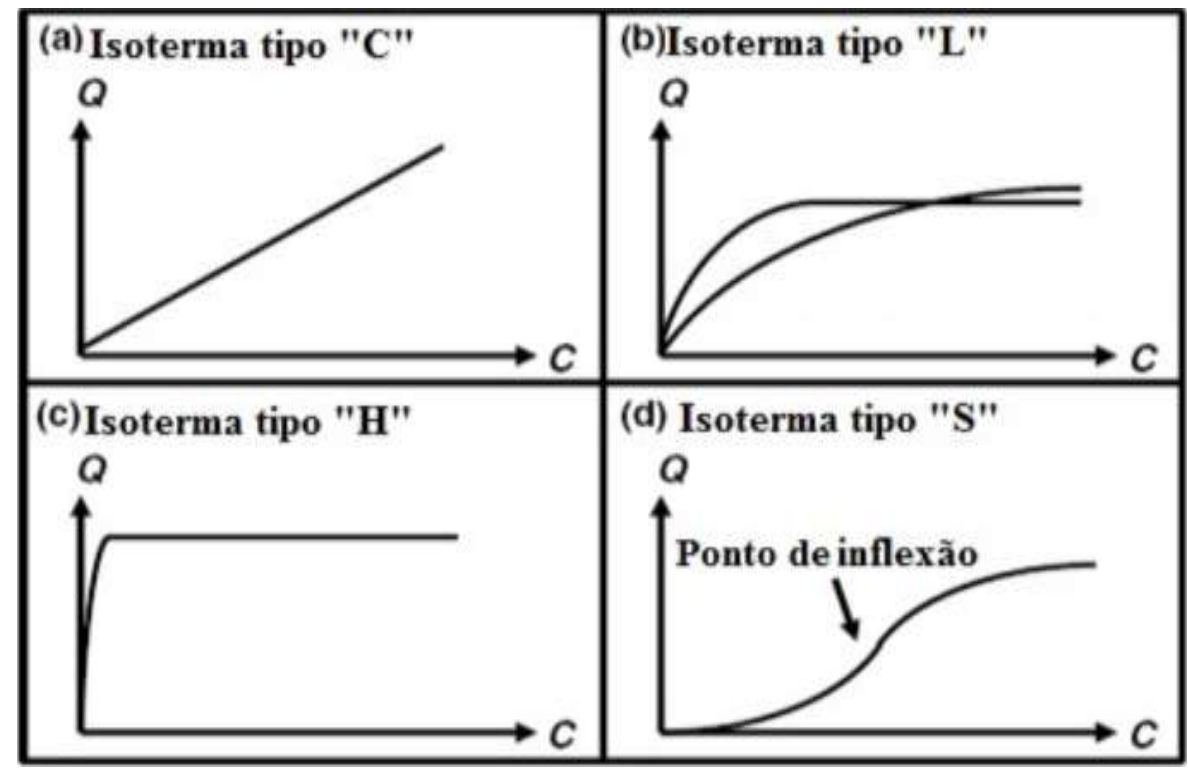

Fonte: Adaptado de Limousin, et al., (2007).

Nestes aspectos, a isotermo tipo "C" nada mais é do que uma reta que parte da origem, isso significa que a concentração do composto em solução adsorvida no sólido é o mesmo em qualquer situação, esta proporção é chamada de coeficiente de distribuição $\left(K_{d}\right)$. Esse tipo de isoterma é frequentemente utilizada para concentrações muito baixas, sem que haja descrição precisa (Santos, 2016).

Por outro lado, a tipo "L", possui curva côncava, devido a relação entre a concentração do composto adsorvido e o que permanece em solução que irá se elevar quando a concentração inicial do soluto aumentar, consequentemente, a saturação progressiva do sólido. Além disso, possuem dois grupos: (1) Assintótica rigorosa (capacidade de adsorção do sólido limitada); (2) Onde o adsorvente, não mostra capacidade de adsorção limitada de forma clara (Rocha, 2017).

Quanto a isoterma do tipo "H", nada mais é do que um caso particular da isoterma "L", em que a uma elevação considerável da curva. Todavia, a do tipo "S" possui forma segmoidal, com ponto de inflexão, este tipo de isoterma possui um fenômeno chamado de adsorção cooperativa (Ludwig, 2018).

Nesse sentido, a partir das correlações dos dados experimentais aos modelos matemáticos das isotermas de adsorção, é possível estimar a quantidade total de adsorvente necessária para o processo e expressar graficamente. Para representar as isotermas, os modelos mais utilizados hoje foram desenvolvidos por Herbert Max Finlay Freundlich (1880 - 1941) e Irving Langmuir (1881- 1957). Dentre estes, Freundlich é o mais utilizado, formulado no ano de 1912 (Takeshita, et al., 2019).

\subsubsection{Isoterma de Langmuir}

O modelo de Langmuir indica que o processo de adsorção acontece em superfície homogênea, capaz de formar monocamada, sem relação entre espécies adsorvidas (Equação 1). Em outras palavras, sem qualquer interação entre moléculas em sítios de adsorção vizinhos (Almeida, et al., 2017).

$$
q_{e}=\frac{K_{1} \cdot q m \cdot C_{e}}{1+K_{1} C_{e}}
$$

Neste contexto, tem-se a forma linear da isoterma de Langmuir (Equação 2).

$$
\frac{C_{e}}{q_{e}}=\frac{1}{q m \cdot K_{1}}+\frac{C_{e}}{K_{1}}
$$


Onde: $q e=$ Quantidade da espécie adsorvida por massa de adsorvente $\left(\mathrm{mg} / \mathrm{g}^{-1}\right) ; C e=$ concentração do adsorvato em solução que está em equilíbrio com a quantidade adsorvida $\left(\mathrm{mg} / \mathrm{L}^{-1}\right) ; C 0=$ Concentração inicial do adsorvato $\left(\mathrm{mg} / \mathrm{L}^{-1}\right) ; q m=$ Capacidade máxima de adsorção $\left(\mathrm{mg} / \mathrm{g}^{-1}\right) ; K l$, constante de equilíbrio de Langmuir $\left(\mathrm{L} / \mathrm{mg}^{-1}\right)$.

A curva da isoterma de Langmuir apresenta, como característica fundamental, uma constante adimensional denominada, parâmetro de equilíbrio (RL), ou fator de separação, (Equação 3), (Boukhemkhem, 2017).

$$
R_{L}=\frac{1}{1+K_{1} c_{0}}
$$

Se $\mathrm{R} L>1$ a isoterma formada será desfavorável; Se $\mathrm{R} L=0$ a adsorção torna-se irreversível; Se $\mathrm{R} L=1$ a formação da isoterma e linear; se $0<\mathrm{R} L<1$ a isoterma e favorável.

\subsubsection{Isoterma de Freundlich}

Em 1906, Herbert Max Finlay Freundlich (1880 - 1941) desenvolveu o primeiro modelo matemático conhecido para descrever processos de adsorção. Este sistema, é amplamente utilizado nos procedimentos em multicamadas e superfícies heterogêneas (Araújo, et al., 2018).

Quanto a isoterma de Freundlich, trata-se de uma equação empírica com adsorção em sítios não uniformes. Neste sentido, a adsorção para este modelo ocorre com a formação de multicamadas (energias de adsorção diferentes) com forte interação entre moléculas (Cardoso, et al., 2020). Este modelo matemático é muito utilizado para descrever capacidade adsortiva de um determinado sólido em meio aquoso (Equação 4).

Desse modo, a forma não linear do modelo de Freundlich é dada pela expressão:

$$
q_{e}=K_{1} \cdot C_{e}^{1 / n}
$$

Onde: $q e=$ Quantidade da espécie adsorvida por massa de adsorvente $\left(\mathrm{mg} / \mathrm{g}^{-1}\right) ; C e$ é a concentração do adsorvato em solução $\left(\mathrm{mg} / \mathrm{L}^{-1}\right) ; K_{1}=$ Constante de Freundlich $\left(\mathrm{L} / \mathrm{mg}^{-1}\right) ; n=$ intensidade de energia no processo de adsorção (adimensional). Além disso, para valores de $1<n<10$ corresponde a adsorção favorável (Toor, Jin, 2012).

\section{4 cinética de adsorção}

Dentre os estudos realizados para caracterizar o processo de adsorção, a cinética tem sido fundamental na remediação dos danos causados pelo descarte incorreto efluentes. Além disso, descreve a velocidade com que as moléculas do adsorvato são adsorvidas pelo material adsorvente(sólido). Nesse aspecto, a cinética considera os fenômenos de transferência de massa, o qual é parâmetro importante nos estudos de adsorção, pois fornece o tempo de equilíbrio (Naushad, et al., 2019)

Partindo desse princípio, a cinética auxilia na descoberta do tipo de mecanismo envolvido e das etapas de controle para se determinar a eficácia da adsorção. Ademais, é utilizado para o dimensionamento de sistemas para o tratamento de águas residuárias, e também, fornece informações importantes requeridas para aplicação adsorção em escala industrial (Lermen,2017).

Para que isso ocorra, a cinética depende das características físico-químicas, como por exemplo tamanho das moléculas de adsorvato e adsorvente, bem como a distribuição e diâmetro dos poros, interações entre adsorvente e adsorvato, além da variabilidade do efluente a ser tratado (Schimmel, 2008).

Dessa forma, com propósito de analisar as etapas controladoras do processo de adsorção, são utlilizados modelos cinéticos para leitura e expressão de dados experimentais. Dentre estes, os modelos matemáticos de cinética mais utilizados são: Pseudo-primeira ordem; de Pseudo-segunda ordem e Difusão intrapartícula (Sales, et al., 2015). 


\subsubsection{Pseudo-Primeira Ordem}

O modelo cinético de pseudo-primeira ordem baseia-se na hipótese de que a variação da quantidade de soluto é adsorvida com o tempo (Equação 5), sendo diretamente proporcional a diferença entre a quantidade do soluto adsorvida no equilíbrio e quantidade adsorvida em um tempo qualquer (Andrade, et al.,2015).

$$
\frac{d q(t)}{d t}=k_{1}\left(q_{e}-q_{t}\right)
$$

Integrando a equação acima para as circunstâncias de contorno $t=0$ a $t=t q_{e}=0$ a $q=q_{t}$ têm-se (Equação 6):

$$
q_{t}=q_{e}\left[1-\exp \left(-k_{1} t\right)\right]
$$

Em que $q_{e}$ e $q_{t}\left(\mathrm{mg} / \mathrm{g}^{-1}\right)$ podem ser definidas como as capacidades de adsorção no equilíbrio e em um tempo $t$ qualquer, respectivamente e $k_{1}\left(\mathrm{~L} / \mathrm{min}^{-1}\right)$ a constante cinética de pseudo-primeira ordem. Nestas perspectivas, esta equação é uma das mais utilizadas para a velocidade de adsorção do soluto em solução líquida (Ho, 2006).

\subsubsection{Pseudo-Segunda Ordem}

O modelo cinético de pseudo-segunda ordem, baseia-se na capacidade de adsorção na fase sólida (Equação 7). Partindo do pressuposto que, a velocidade da reação é dependente da quantidade do soluto adsorvido na superfície do adsorvente e da quantidade adsorvida no equilíbrio (Ho, Mckay, 1999).

$$
\frac{d q_{t}}{d t}=k_{2}\left(q_{e}-q_{t}\right)^{2}
$$

Integrando a equação acima para as premissas de contorno $t=0$ a $t=t$ e $\mathrm{q}=0$ a q $=\mathrm{qt}$ (Equação 8):

$$
q_{t}=\frac{k_{2} q_{e}^{2} t}{1+\left(q_{e} k_{2} t\right)}
$$

Onde $t$ é tempo de adsorção; $q_{e}$ e $q_{t}$ são as quantidades adsorvidas do adsorvato no equilíbrio e no tempo $t ; k_{2}$ é a constante da velocidade de adsorção de pseudo-segunda ordem. Este modelo cinético de pseudo-segunda ordem é aplicado para sistemas cujos modelos de forças impulsoras não são lineares. Dessa maneira, esta equação tem sido amplamente utilizada para descrever sistemas adsortivos envolvendo íons metálicos, corantes, herbicidas, óleos e substâncias orgânicas em soluções aquosas (Campos, et al., 2018).

\subsubsection{Difusão Intrapartícula}

O modelo de difusão intrapartícula, ou modelo de Weber e Morris, pode ser adotado em sistemas de adsorção que tem como etapa limitante da velocidade a difusão intrapartícula (Equação 9). Se a difusão for fator determinante da velocidade, a remoção do adsorvato variará com a raiz quadrada do tempo (Uchôa, 2019).

$$
q_{e}=k_{i} t^{1 / 2}+C
$$

Onde $t$ é o tempo (min) de adsorção; $q_{e}$ é a quantidade de adsorvida de adsorvato no tempo $t ; k_{i}$ é a constante da velocidade de adsorção do modelo de difusão intrapartícula (mg/g. $\left.\min ^{1} 1 / 2\right) ; C$, constante de espessura da camada limite (mg. $\mathrm{g}^{-}$ $\left.{ }^{1}\right)$. 


\subsection{Carvão ativado (CA)}

Material de estrutura porosa, o CA conta com elevada área superficial, que, além de apresentar baixa quantidade de heteroátomos, é extremamente rico em carbono (C) na sua composição. O tamanho dos poros se classifica em: Macroporos (>50 $\mathrm{nm}$ ); Mesoporos ( $>2 \mathrm{~nm}$ e $<50 \mathrm{~nm}$ ); Microporoso ( $<2 \mathrm{~nm}$ ). Essa variação porosa lhe permite capacidade de adsorção de moléculas líquidas e sólidas em seu interior (Almeida,et al., 2017). Desse modo, a porosidade é importante, pois, uma vez que o adsorvente possuir maior diversidade em tamanho e quantidade de poros, mais satisfatória será a capacidade de adsorção. Os macros e mesoporos presentes nos carvões no solido também são essenciais, por permitir a acessibilidade das moléculas de adsorbato para o interior das partículas de adsorvente, especialmente nas aplicações em fase líquida (Yu, et al., 2019).

O CA pode ser produzido através do processo de carbonização e pirólise materiais orgânicos, como por exemplo carvão (não ativado), madeira, casca de coco, amêndoas ou nozes. Quanto às formas físicas do carvão ativado, elas são classificadas em três tipos: pó, fibroso e granular. Cada um com sua aplicação específica (Oliveira, 2016).

Outro meio de utilização, além do tratamento de água no que diz respeito a remoção de contaminantes (orgânicos e inorgânicos), CA pode ser usado também na medicina, filtros de ar, catalisadores, no armazenamento de gás e em materiais eletrodos como adsorvente de poluentes líquidos e gasosos, eliminando cor, odor e sabor desagradável (Maneerung, et al., 2016).

\subsection{Tipos de ativação}

Quanto aos tipos de ativação, podem ser definidos como elementos responsáveis pelo processo de elevação da área superficial do material, através de reações ocorrentes no mesmo, com métodos químicos e físicos. Dessa maneira, a ativação física consiste na carbonização por meio de pirólise: neste processo ocorre a remoção de materiais que não contém carbono, seguido de exposição a temperaturas que variam de $800^{\circ} \mathrm{C}$ a $1000{ }^{\circ} \mathrm{C}$ (Rimoli, et al., 2019).

Por outro lado, o processo de ativação química é feito pela inserção de elementos químicos nas superfícies do material, a fim de promover aumento da área para adsorção. As principais substâncias ativantes são: Carbonato de sódio $\left(\mathrm{MgCO}_{2}\right)$; Cloreto de alumínio $\left(\mathrm{ALCL}_{3}\right)$; Acido Fosfórico $\left(\mathrm{H}_{3} \mathrm{PO}_{4}\right)$; Hidróxido de Sódio $(\mathrm{NaOH})$; Cloreto de Magnésio $\left(\mathrm{MgCL}_{2}\right)$; Carbonato de Potássio $\left(\mathrm{K}_{2} \mathrm{CO}_{3}\right)$; Cloreto de Zinco $\left(\mathrm{ZnCl}_{2}\right)$; Hidróxido de Potássio $(\mathrm{KOH})$; Cloreto de Alumínio $\left(\mathrm{AlCl}_{3}\right)$. A ativação química oferece inúmeras vantagens, como estrutura porosa controlada, baixa temperatura, pirólise e ativação em uma única etapa, elevado rendimento do material carbonizado e menor tempo de ativação (Costa, furmanski \& dominguini, 2015).

\subsection{Castanha de Caju}

O cajueiro (Anacardium occidentale Linaeus), pertence à família Anacardiaceae, é uma planta originária do Brasil, de clima tropical. Estima-se que esta planta contempla um conjunto de aproximadamente 700 espécies no mundo, sendo 70 destes presentes no território brasileiro (Alencar, et al., 2018).

O caju é composto pelo pedúnculo, pseudofruto do cajueiro, parte suculenta e macia, rica em vitamina $\mathrm{C}$, minerais (cálcio, ferro e fósforo) e alto valor nutritivo, dele é extraída a polpa do caju, muito utilizada na produção de sucos, geleias, doces, refrigerantes, bebidas alcoólicas ou consumida in natura (Schmitz, 2018).

A castanha, verdadeiro fruto do cajueiro, é composta por uma amêndoa oleaginosa, consumida in natura ou torrada, possui importante valor nutricional, rico em proteínas, até $25 \%$, largamente utilizada na culinária, após o processamento industrial é comercializada nos mercados nacional e internacionais (Lima, 2017).

Quanto a sua estrutura e fisiologia, a camada externa da castanha é denominada por pericarpo, e apropria em sua composição: Endocarpo; Epicarpo; Mesocarpo. O epicarpo parte externa; o mesocarpo é a camada intermediária abaixo do epicarpo, material de aspecto esponjoso; o endocarpo é a camada interna da castanha, como uma película que reveste a amêndoa, tem a função de proteger o fruto (Tavares, 2016). 
Do pericarpo é extraído o líquido viscoso (LCC), utilizado na indústria química e na fabricação de tintas, vernizes, lubrificantes. Desse líquido podem ser extraídos o cardol, óleo cáustico e combustível, que podem ser utilizados como imunizantes de madeira e na indústria de aeronaves (Albuquerque, et al., 2019).

Os resíduos provenientes desses processos, geralmente são utilizados pela indústria agrícola como adubo ou na produção de biocarvões, pois sua composição inclui basicamente alto teor de carbono e matéria orgânica. Todavia, pode-se agregar valor a esses resíduos, gerando assim novos produtos de interesses econômicos e ambientais (Trazzi, et al., 2018).

\section{Metodologia}

\subsection{Métodos Aplicados}

O método aplicado foi o experimental, com enfoque descritivo das situações observadas e registrada da maneira como ocorrem, onde objeto de estudo é submetido a influência de variáveis, em situações controladas e previamente conhecidas (Prodanov, Freitas, 2013). De forma quali-quanti, onde resultados numéricos são relacionados aos qualitativos (Pereira, et al.,2018). Complementado com o levantamento de dados documentais, cujo recorte temporal situou-se entre 2008 a 2020, com inserção de estudos pioneiros. Os descritores aplicados para a seleção dos documentos foram: Carvão ativado; Adsorção; Tratamento de efluentes; Corantes; Equilíbrio e cinética de adsorção.

\subsection{Preparo das amostras}

A matéria prima utilizada na pesquisa foi o material percursor de origem vegetal, resíduo oriundo da produção de amêndoas da castanha de Caju (Anacardium occidentale). Foram coletados $1 \mathrm{~kg}$ de biomassa casca torrefada $\left(200^{\circ} \mathrm{C}\right)$, utilizada para extração de LCC - Técnico, fabricado e cedido pelo Laboratório de Engenharia e Produtos Florestais - LAEPF, da Universidade do Estado do Pará -UEPA campus-VI, Paragominas. Em seguida, o material selecionado foi lavado em água corrente para a retirada do excesso de impurezas, e então submetidos a secagem em estufa, à temperatura de $103{ }^{\circ} \mathrm{C}$ durante 24 horas, a fim de remover-se a umidade do material.

\subsection{Produção do Carvão ativado (CA)}

A produção do carvão ativado foi realizada no Laboratório de Engenharia e Produtos Florestais - LAEPF, na Universidade do Estado do Pará -UEPA campus-VI, Paragominas.

Para a transformação dos resíduos em carvão ativado (Figura 2), foi utilizado a metodologia adaptada de Castro et al. (2019). Nesse sentido, após o processo de secagem, os resíduos da castanha de caju foram pesados, e imersos em solução ativante de hidróxido de sódio $(\mathrm{NaOH})$, previamente preparada ( $80 \mathrm{~g}$ de $\mathrm{NaOH}$ para 1 litro de água destilada). Após impregnação total da casca pelo agente ativante, as amostras foram secas em estufa durante 24 horas na temperatura de $103{ }^{\circ} \mathrm{C}$ antes de seguir para a etapa de pirólise.

Em seguida, as amostras impreguinadas foram inseridas em reator retangular alocado em um forno elétrico tipo mufla para realização do tratamento térmico a $400{ }^{\circ} \mathrm{C}$, com taxa de aquecimento de $10^{\circ} \mathrm{C} / \mathrm{min}$ e tempo de residência de 60 minutos na temperatura final. Ao fim da pirólise, o resfriamento ocorreu de forma natural e gradativa, e em seguida foi lavado várias vezes com água destilada a fim de se retirar o excesso do agente químico ativante e até o lixiviado da lavagem atingir o pH próximo ao neutro, e então o material ser novamente submetido ao processo de secagem à temperatura de $60^{\circ} \mathrm{C}$ por 2 horas. 
Figura 2 - amostra do carvão após ativação.

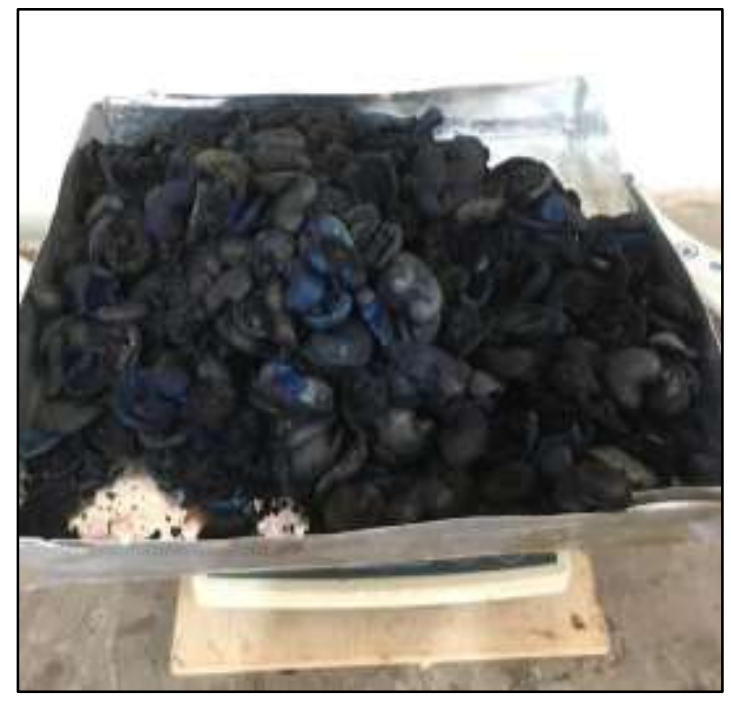

Fonte: Autores (2020).

Após a ativação, o material foi triturado e peneirado, com o intuito de se obter o tamanho desejado das partículas do adsorvente. As peneiras utilizadas possuíam tamanhos de abertura Tyler Mesh 40-35, considerado carvão ativado granular (Araújo, et al., 2018).

\subsection{Caracterização do Carvão Ativado (CA)}

\subsection{1 Área Superficial Especifica $\left(S_{B E T}\right)$}

As isotermas de adsorção e dessorção de nitrogênio foram obtidas em um equipamento Micromeritics Tristar II modelo 3020, para determinação da área superficial específica $\left(\mathrm{S}_{B E T}\right)$ e o tamanho médio dos poros das amostras. Antes das medidas, aproximadamente $0,1 \mathrm{mg}$ de amostra foram submetidas a um pré-tratamento sob vácuo, a $300{ }^{\circ} \mathrm{C}$ por $3 \mathrm{~h}$. Os resultados da área superficial foram determinados pelo método padrão de Brunauer-Emmett-Teller (BET). O volume de poros e o diâmetro de poros foram obtidos de acordo com o método de Barret-Joyner-Halenda (BJH). A análise foi realizada no Laboratório de Óleos da Amazônia (Parque de Ciências e Tecnologia do Guamá - PCT).

\subsubsection{Espectrometria de Infravermelho com Transformada de Fourier (FTIR)}

O FTIR é utilizado para verificação e mensuração dos grupos funcionais orgânicos. Neste sentido, os espectros de infravermelho foram obtidos em um espectrômetro Thermo, modelo nicolet is5, com varredura na região entre $4000 \mathrm{a} 400 \mathrm{~cm}^{-1}$. As amostras foram preparadas com pastilhas de brometo de potássio (KBr). A análise foi realizada no Laboratório de Óleos e Derivados da Amazônia, localizado no Parque de Ciência e Tecnologia do Guamá - PCT, município de Belém - Pará.

\subsubsection{Análise Termogravimétrica e Termo Diferencial (ATG/ATD)}

O ensaio de ATG/ATD foi realizado em equipamento da marca Shimadzu, modelo ATG-50, seguindo as condições de análise a seguir: Amostra é pesada continuamente, em uma balança analítica sensível, acoplada ao forno, enquanto a temperatura é modificada desde a temperatura ambiente até $1000^{\circ} \mathrm{C}$, a razão de aquecimento é de $20^{\circ} \mathrm{C} / \mathrm{min}$, em atmosfera de nitrogênio, operando com vazão de $50 \mathrm{~mL} / \mathrm{min}$. A análise foi realizada no Laboratório de Óleos e Derivados da Amazônia, localizado no Parque de Ciência e Tecnologia do Guamá - PCT, município de Belém - Pará.). 


\subsubsection{Microscopia Eletrônica de Varredura (MEV) e Espectroscopia por Energia Dispersiva (EDS)}

Para a análise textural, estrutural e química das amostras de carvão ativado, foi utilizada a técnica de Microscopia Eletrônica de Varredura (MEV) e Espectroscopia por Energia Dispersiva (EDS). Foi utilizado o equipamento Microscópio Eletrônico de Varredura, modelo Shimadzu, equipado com um espectrômetro de energia dispersiva de raios X (EDS) AZTec Energy X-Act, Oxford. A análise foi realizada no Laboratório de Engenharia de Materiais do Instituto Federal do Pará (IFPA) município de Belém - Pará.

\subsection{Ensaios de adsorção}

Os ensaios de adsorção foram realizados no Laboratório de Química da Universidade do Estado do Pará (UEPA) Campus -VIII, Marabá-PA. O corante utilizado na pesquisa foi o Verde Malaquita (Verde Básico 04).

\subsubsection{Equilíbrio de adsorção}

Para os ensaios de equilíbrio de adsorção, foram utilizados $20 \mathrm{mg}$ de adsorvente e volume de solução de $50 \mathrm{~mL}$ em Elernmeyers de $250 \mathrm{~mL}$, concentrações que variaram de $100-280 \mathrm{mg} / \mathrm{L}^{-1}$ para o corante Verde Malaquita. Estes foram acondicionados em Banho Maria com agitação Dubnoff em temperatura constante de $30{ }^{\circ} \mathrm{C}$, e 90 rotações por minutos (RPM), durante $12 \mathrm{hrs}$.

As concentrações de equilíbrio foram analisadas logo após o término dos ensaios, no espectrofotômetro, marca Agilent Technologies Cary 60 UV-Vis, no comprimento de onda $617 \mathrm{~nm}$.

O equilíbrio na forma de uma expressão matemática (Equação 10).

$$
\mathrm{Qe}=\frac{\left(\mathrm{C}_{0}-\mathrm{C}_{\mathrm{e}}\right) \cdot \mathrm{V}}{\mathrm{m}}
$$

Onde:

$\mathrm{C}_{0}$ é a concentração inicial do corante $\left(\mathrm{mg} / \mathrm{L}^{-1}\right)$;

$\mathrm{C}_{\mathrm{e}}$ é a concentração da solução após atingir o tempo de equilíbrio $\left(\mathrm{mg} / \mathrm{L}^{-1}\right)$;

V é o volume da solução em litros; e

$m$ é a massa do adsorvente ( $\mathrm{g}$ ).

Além disso, foi efetuado o estudo referente ao feito da concentração inicial do adsorbato, com propósito de se saber a quantidade em porcentagem de remoção do corante, assim como a capacidade de adsorção do sólido.

\subsubsection{Cinética de adsorção}

Quanto aos ensaios de cinética de adsorsão, foram utilizados $20 \mathrm{mg}$ de adsorvente para um volume de solução de $50 \mathrm{ml}$ em Erlenmeyers de $250 \mathrm{ml}$, com concentração inicial do corante Verde Malaquita de $100 \mathrm{mg}$. $\mathrm{L}^{-1}$, em temperatura de $30{ }^{\circ} \mathrm{C}$ e tempos de contato de 5, 10,15, 20, 30, 40, 60, 90, 120, 240, 360 e 400 minutos, mantendo todas as demais variáveis constantes.

As concentrações de equilíbrio foram analisadas logo após o término dos ensaios, no espectrofotômetro, marca Agilent Technologies Cary 60 UV-Vis, ajustados no comprimento de onda $617 \mathrm{~nm}$, para corante verde malaquita, a fim de analisar-se os modelos cinéticos de pseudo-primeira ordem, pseudo-segunda ordem e difusão intraparticula foram testados.

\subsection{Tratamento dos dados}

Os dados foram tratados no Software origin, assim como parâmetros de equilibrio(i e cinética de adsorção foram estimados por regressão não linear. 


\section{Resultados e Discussão}

\subsection{Caracterização do Carvão Ativado (CA)}

\subsubsection{Espectroscopia de Infravermelho com Transformada de Fourier (FTIR)}

Os dados obtidos e analisados quanto ao FTIR indicam vários picos de adsorção, o que corresponde a diferentes tipos de grupos funcionais. Partindo desse pressuposto, as bandas alongadas, $3325,63 \mathrm{~cm}^{-1}$ e $3390 \mathrm{~cm}^{-1}$, relacionam-se ao grupo catiônico responsáveis pelas ligações hidroxilas $(\mathrm{OH})$ e carboxila $(-\mathrm{COOH})$. Ademais, valores evidenciados nas bandas 1770

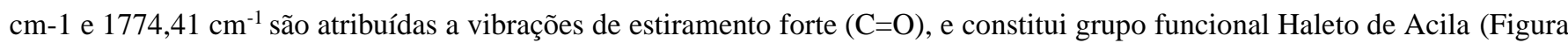
$3)$.

Além disso, os picos em 1439,58 $\mathrm{cm}^{-1}$ e 878,68 $\mathrm{cm}^{-1}$ apresentam, respectivamente, estiramento (C-O), grupo éteres, e modo de deformação fora do plano (C-H) para diferentes anéis de benzeno substituídos. Por outro lado, 457,84 $\mathrm{cm}^{-1}$ a 410,00 $\mathrm{cm}^{-1}$ indicam o estiramento do grupo $(\mathrm{C}-\mathrm{C} ; \mathrm{C}-\mathrm{H})$ associado muito provavelmente a presença de anéis aromáticos.

Figura 3 - Espectro na região do infravermelho com Transformada de Fourier (FTIR) para o carvão ativado

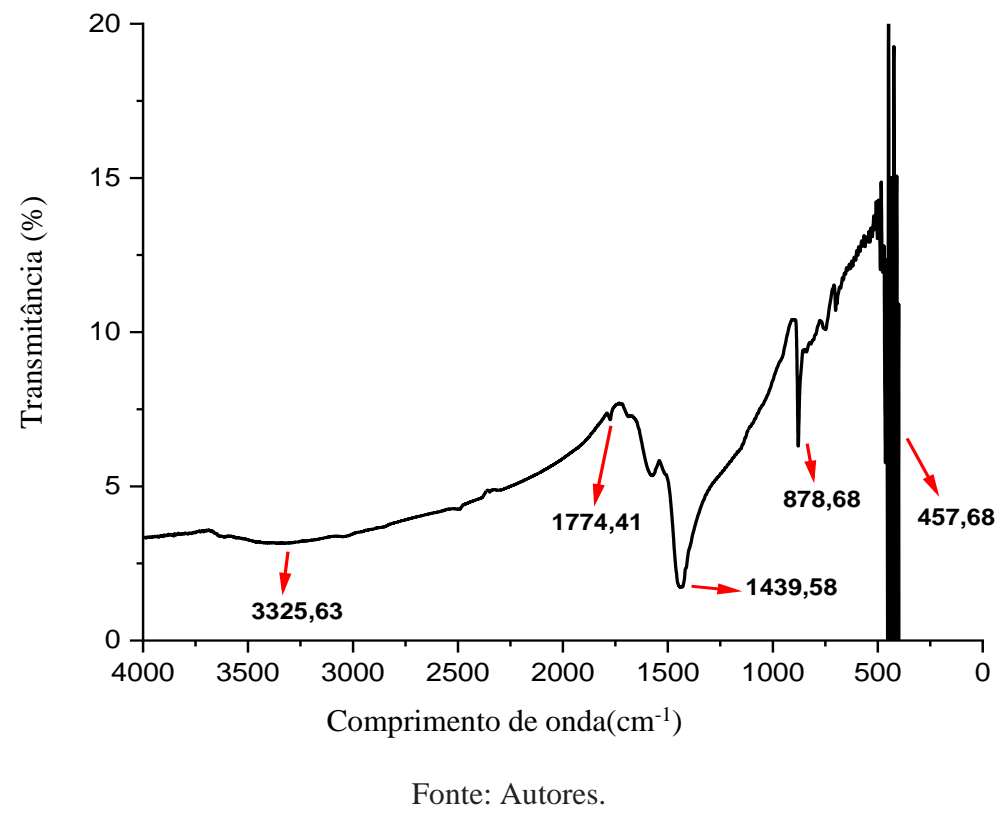

Em estudo realizado por Souza et al. (2018), com corantes básicos, concluiu que o carvão ativado, cuja superfície é composta por grupos funcionais ácidos e hidroxilas $(\mathrm{OH})$, tem potencial para adsorver elementos catiônicos por interações eletrostáticas. Além disso, afirmam em sua pesquisa que presença de ácidos carboxilas $(-\mathrm{COOH})$ indica afinidade com adsorvatos catiônicos.

Venkataraghavan, Thiruchelvi e Sharmila (2020), evidenciaram picos nas bandas $1249,87 \mathrm{~cm}^{-1}$ e $1149,57 \mathrm{~cm}^{-1}$ responsáveis por éter aromático $(\mathrm{C}-\mathrm{O})$, e que a interação entre adsorvato e adsorvente ocorre devido a três mecanismos: eletrostática (Interação não ligada entre duas cargas opostas de moléculas de adsorvente e corante); Interações hidrofílicohidrofóbicas (presença de grupos aromáticos não polares entre o corante e o grupo - CH3 na superfície do adsorvente). Isto explica o favorecimento na interação adsorvato-adsorvente, entre o carvão ativado do mesocarpo esponjoso da castanha do caju (Anacardium occidentale) e o corante catiônico Verde Malaquita. 


\subsubsection{Análise Termogravimétrica (ATG) e Termo Diferencial (ATD)}

A análise dos dados obtidos quanto a ATG e ATD, indicaram diversos picos endotérmicos. Neste sentido, o primeiro pico das amostras evidencia temperatura por volta dos $43,70{ }^{\circ} \mathrm{C}$, já o segundo em aproximadamente $127{ }^{\circ} \mathrm{C}$, que está associado a perda de água adsorvida pelas amostras. Ademais, destacam-se picos localizados respectivamente nas temperaturas $671{ }^{\circ} \mathrm{C} \mathrm{e}$ $948^{\circ} \mathrm{C}$ (Figura 4).

Figura 4 - Análise termogravimétrica dos carvões ativados.

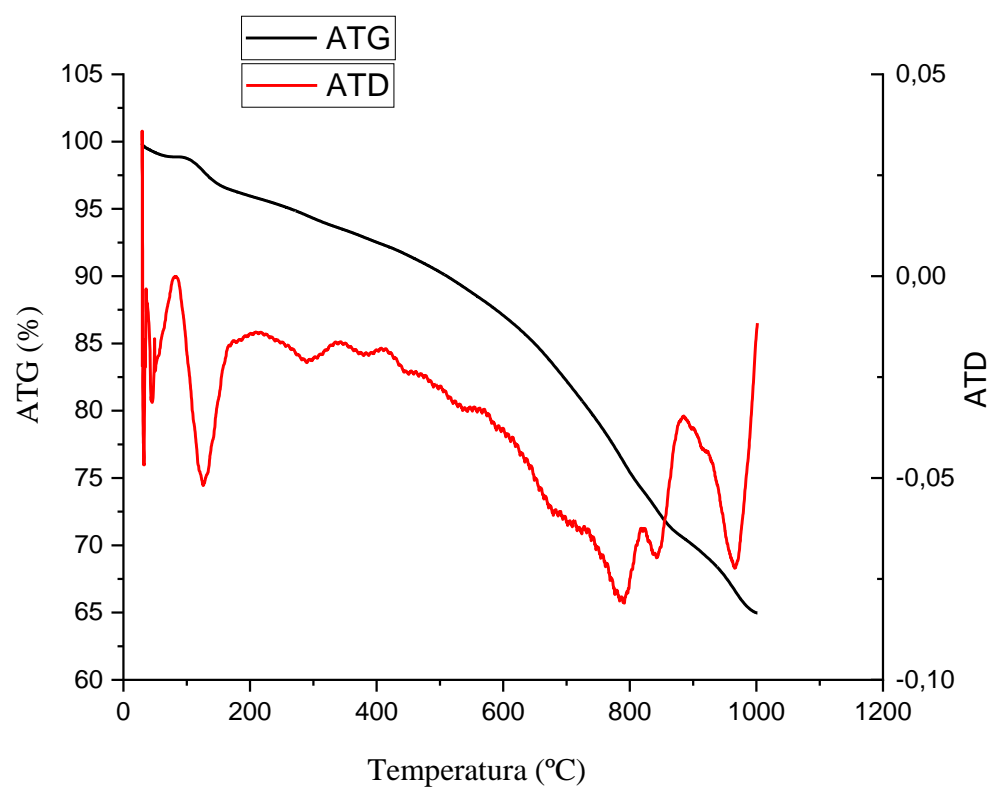

Fonte: Autores.

Souza et al. (2019), com pesquisa similar, em que a mesma indicou picos endotérmicos em 100, 600 e $650{ }^{\circ} \mathrm{C}$, respectivamente, desse modo, concluíram que resultados nessa faixa de temperatura caracterizam perda de água e grupos funcionais em decomposição nas superfícies do adsorvato.

Campos (2018) ao preparar carvão ativado de resíduos agroindústrias, indicou que temperaturas com picos, na faixa de $400{ }^{\circ} \mathrm{C}$, é referente à degradação de hemicelulose, algumas ligninas e celulose. Todavia, os dados para o presente estudo indicaram baixo pico endotérmico, na faixa de $400{ }^{\circ} \mathrm{C}$, com pouca degradação de ligninas, hemicelulose e celulose. Isto pode ser explicado pelo fato do material percursor (mesocarpo da castanha de caju) já se encontrara torrefado, uma vez que, haviam sido objeto de estudo de outra pesquisa semelhante.

\subsubsection{Microscopia Eletrônica de Varredura (MEV) e Espectroscopia por Energia Dispersiva (EDS)}

Os resultados obtidos, referentes às micrografias das superfícies das amostras de carvão ativado, indicaram partículas sólidas características de processos de ativação e carbonização que se encontram empilhadas e aglomeradas, com efeito, gera agregados de morfologia irregular com contornos definidos após a eliminação dos grupos voláteis e formação de impurezas, além disso, possui superfícies ásperas para ambas as amostras (Figura 5). 
Figura 5 - Microscopia de varredura eletrônica: A(100x); B(50x).

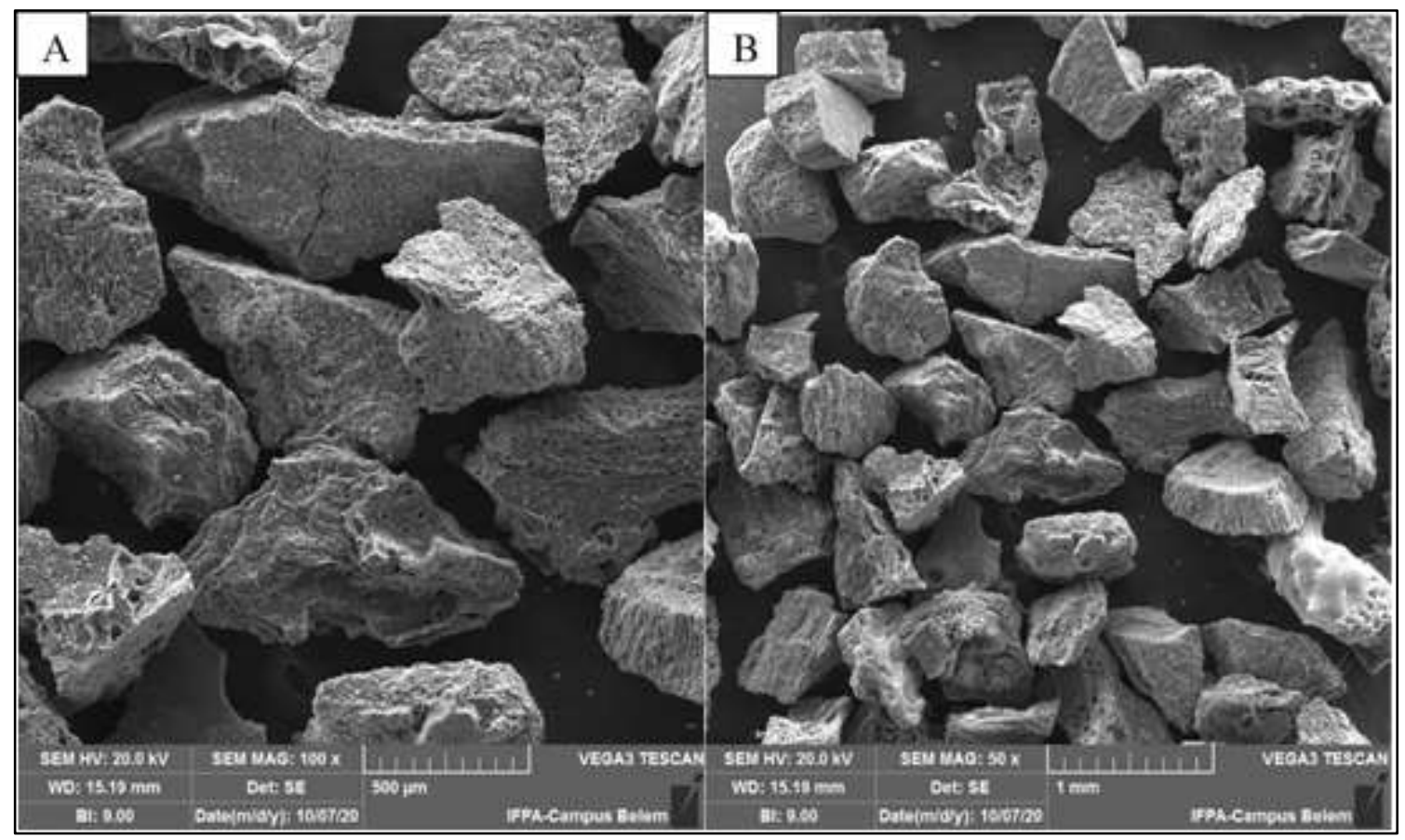

Fonte: Autores (2021).

Em relação a presença de poros, estudo efetuado a, por Popa e Visa (2017), sobre a síntese, ativação e caracterização de pó de carvão vegetal, concluiu que a predominância de microporos e mesoporos está relacionada ao agente ativante (NaOH), pois este adentra para o interior da lacuna e favorece a desobstrução que resulta em um aumento no número de poros menores.

A presença de poucos poros pode estar relacionada com o processo de ativação, pois, segundo estudo realizado por Du, et al. (2019) com carvão ativado de madeira de safena e derivados, se o processo ativação não for consistente, o CA pode apresentar menos poros, haja vista que a ativação exerce papel fundamental na desobstrução dos sítios de adsorção.

Além disso, para as micrografias obtidas, o material apresenta estrutura microscópica compacta, semelhante à estrutura obtida pela carbonização de outros materiais à base de celulose (Figura 6). Ademais, indicou-se pontos claros que evidenciam características de material denso, provavelmente Hidróxido de Sódio $(\mathrm{NaOH})$ residual do processo de ativação química 
Figura 6 - Microscopia de varredura eletrônica (1000x).

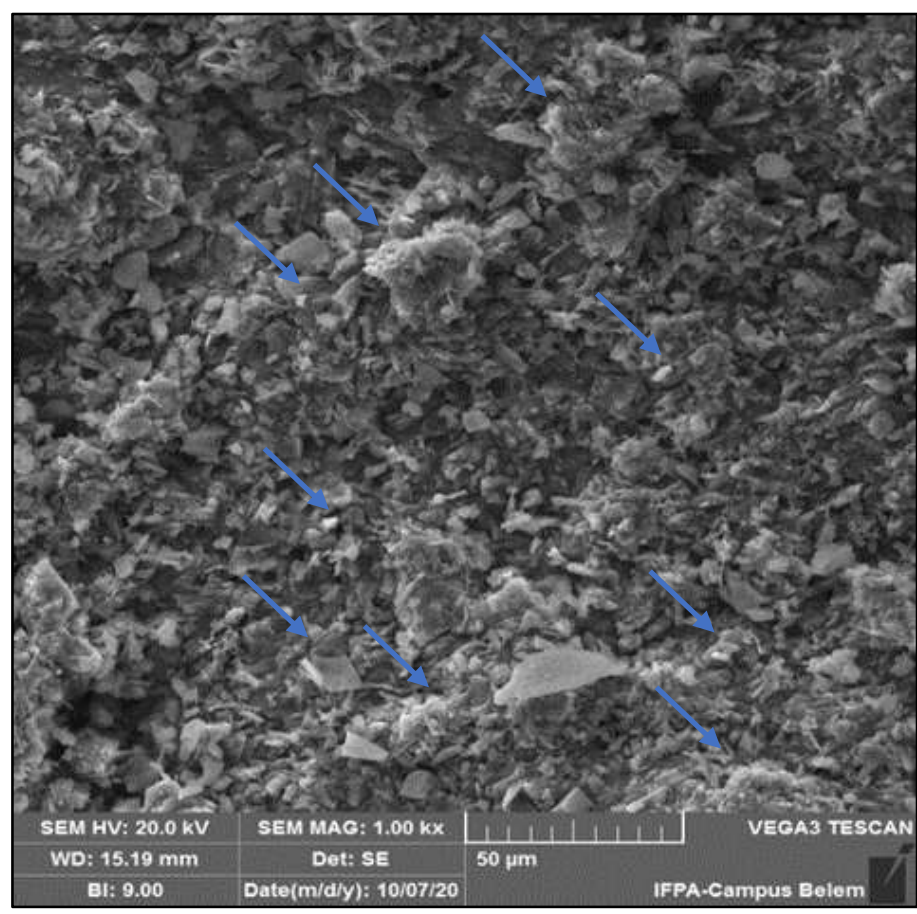

Fonte: Autores (2021).

Costa, Furmanski e Dominguini (2016), com carvão ativado quimicamente com Casca de Nozes, evidenciou que partes mais claras aparentes em micrografias representam resquícios do elemento químico ativante, corroborando com esta pesquisa. Os resultados obtidos quanto a Espectroscopia por Energia Dispersiva - EDS (Figura 7), indicaram, índices elevados de Oxigênio $(\mathrm{O}=46,94 \%)$, seguido de Carbono $(\mathrm{C}=34,66 \%)$ e um significativo aumento percentual de Sódio $(\mathrm{Na}=16,13 \%)$. Nesse sentido, no carvão ativado há presença de Alumínio $(\mathrm{Al}=1,61 \%)$. Por outro lado, os dados evidenciaram baixas concentrações para Potássio $(\mathrm{K}=0,55 \%)$ e Calcio $(\mathrm{Ca}=0,1 \%)$, valores quase que insignificantes (Tabela 1$)$.

Tabela 1 - Resultado do EDS para a amostra de carvão ativado.

\begin{tabular}{c|c}
\hline Elementos químicos detectados & Composição (\%) \\
\hline $\mathrm{O}$ & 46,94 \\
\hline $\mathrm{C}$ & 34,66 \\
\hline $\mathrm{Na}$ & 16,13 \\
\hline $\mathrm{Al}$ & 1,61 \\
\hline $\mathrm{K}$ & 0,55 \\
\hline $\mathrm{Ca}$ & 0,1 \\
\hline Total & $\mathbf{1 0 0}$ \\
\hline
\end{tabular}

Fonte: Autores (2021).

Análises pontuais dos elementos químicos, presentes na amostra do carvão, indicaram sinais claros de Carbono (C) e Oxigênio (O) (Figura 7). Nesse contexto, a presença destes elementos químicos favorece a formação de grupo funcionais na superfície do sólido, já citado no FTIR, como por exemplo hidroxilas $(\mathrm{OH})$ e carboxila $(-\mathrm{COOH})$. 
Figura 7 - Espectroscopia por Energia Dispersiva em camadas.

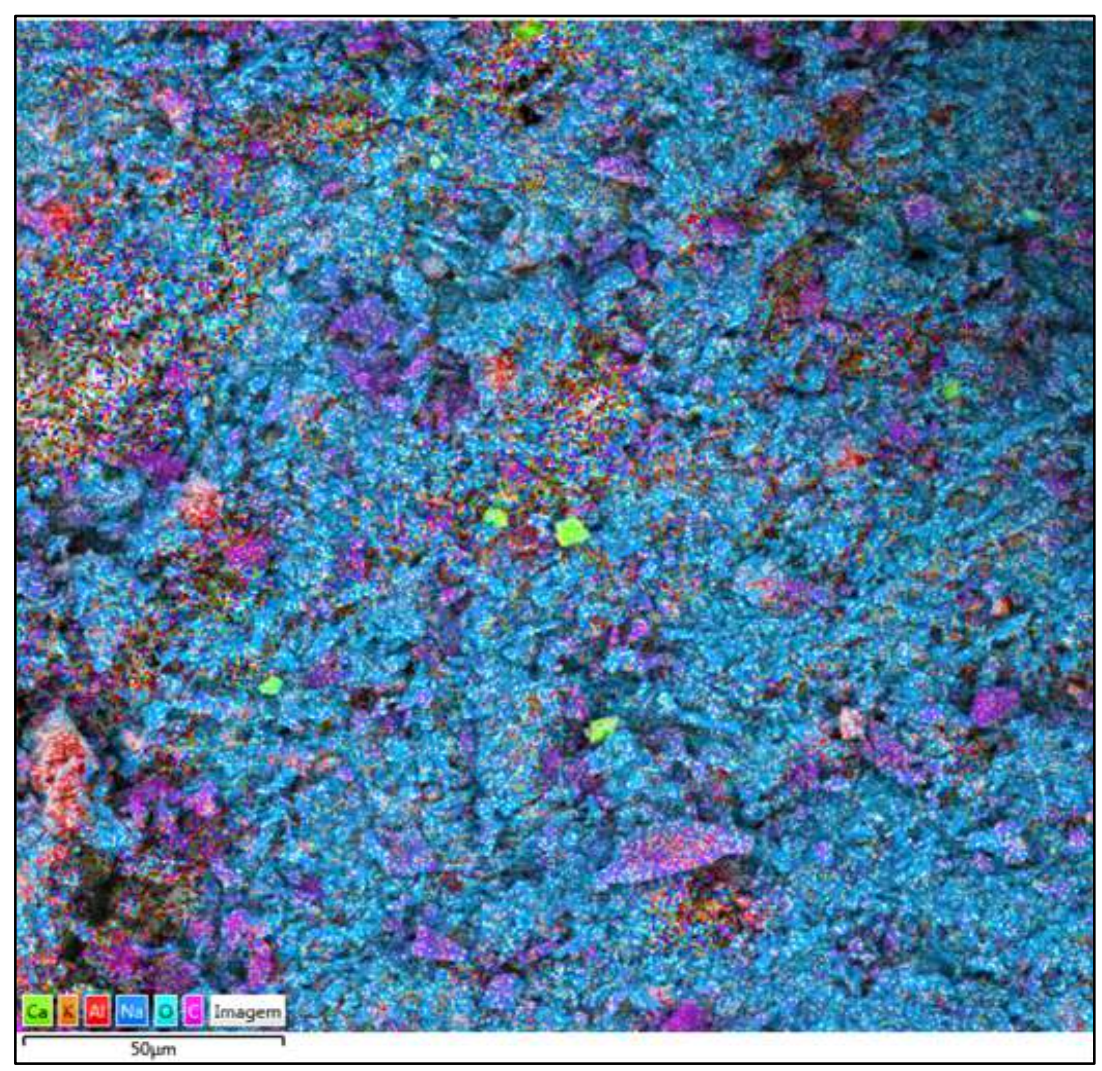

Fonte: Autores (2021).

Consequentemente, segundo Spagnoli, Giannakoudakis e Bashkova (2017), com carvão também da castanha de caju, ativado com cloreto de Zinco $\left(\mathrm{ZnCl}_{2}\right)$, grupos hidroxilas $(\mathrm{OH})$ e carboxila $(-\mathrm{COOH})$, favorecem a adsorção corantes catiônicos, corroborando com esta pesquisa.

No entanto, estudos, por Li et al. (2020), evidenciaram que a presença de oxigênio (O) em elevadas concentrações, pode bloquear os poros, o que, por sua vez, aumenta a capacidade de dessorção e consequentemente diminui a eficácia da adsorção. Por outro lado, o Sódio $(\mathrm{Na}=16,13 \%)$, disposto na superfície, pode estar relacionado a resquícios do agente ativante hidróxido de Sódio $(\mathrm{NaOH})$.

Quanto ao pico de Carbono (C = 34,66\%), por Ries, Silveira (2019), conclui que índices elevados no percentual de Carbono (C) são esperados, levando em consideração a produção de carvão ativado, com material percursor de origem orgânica, pois estes possuem abundância de tal elemento químico em sua composição.

\subsection{4 Área Superficial Especifica $\left(S_{B E T}\right)$ e Porosidade}

Os resultados obtidos na adsorção/dessorção de Nitrogênio $\left(\mathrm{N}_{2}\right)$, para o adsorvente obtido, indicam características pertencentes ao tipo "I" e "II" (Figura 8), conforme a Classificação de Braunauer, Deming e Teller-BDDT (Brunanuer, Emmett $\&$ teller, 1938). Além disso, os dados também indicaram área superficial específica $S_{B E T}=5.6543 \mathrm{~m}^{2} / \mathrm{g}^{-1}$ : 
Figura 8 - Isotermas de adsorção/dessorção de Nitrogênio (2), para carvão ativado da casca da castanha de caju.

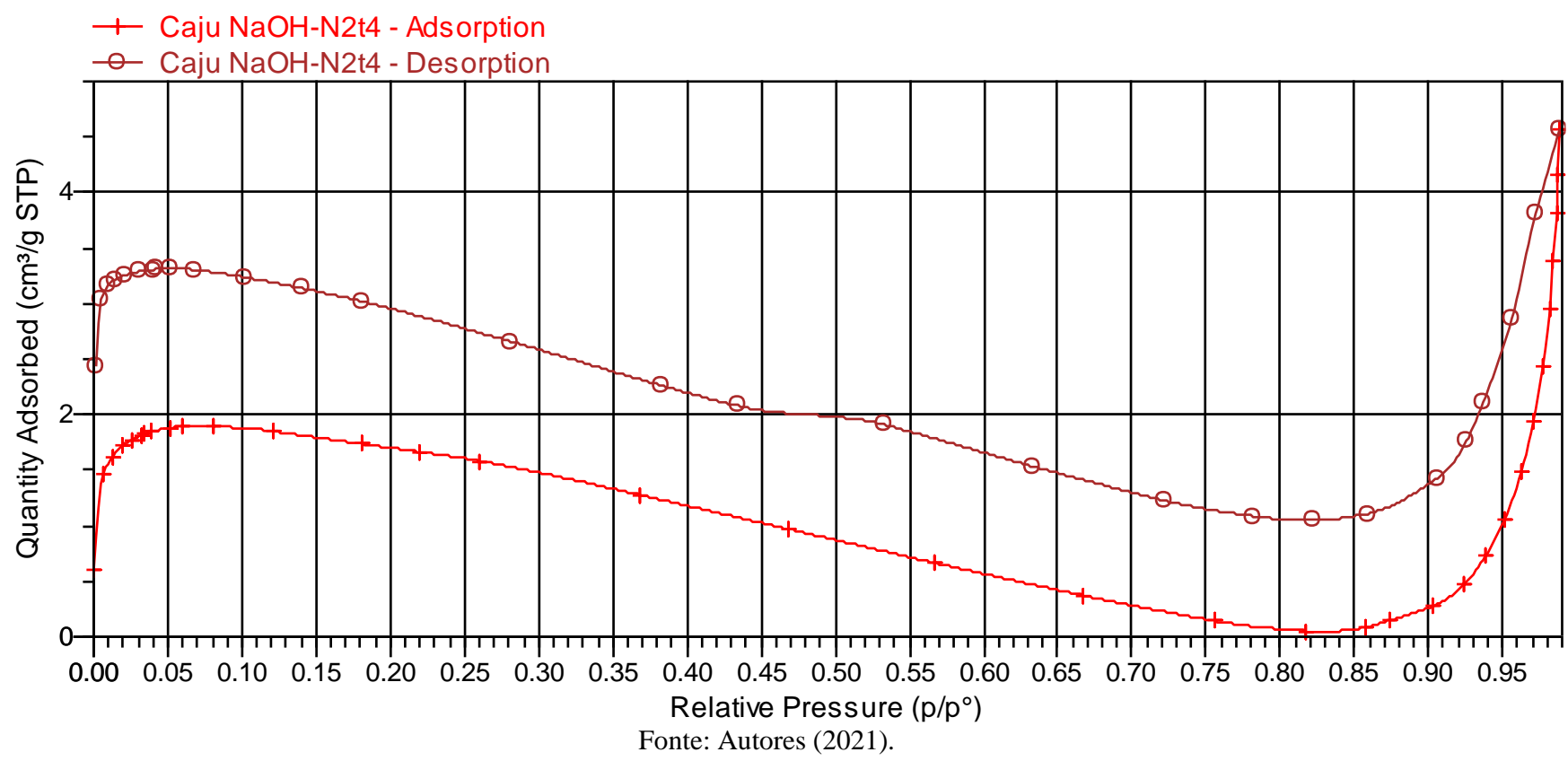

Nesse contexto, Almeida (2015), em seu estudo, afirma que Isotermo tipo "I" acontece de forma comum em sólidos com ocorrência de microporos e variações além do diâmetro molecular do adsorbato. Enquanto que o tipo "II" indica a presença de mesoporos na superfície do adsorvente.

Estes dados diferem dos resultados encontrados por Sales et al. (2015), Caracterização e Aplicação do Carvão Ativado Obtido a partir do Sabugo de Milho (Zea mays). Estes autores obtiveram área superficial específica $S_{B E T}=501 \mathrm{~m}^{2} \cdot \mathrm{g}^{-1}$, porém, diâmetro médio de poros em torno de $20 \AA$ ( $\mathrm{nm}=2)$, caracterizando material micro e mesoporoso.

A baixa área superficial específica $\left(S_{B E T}\right)$ pode ser justificada devido a elevada taxa de Oxigênio $(\mathrm{O}=46,94 \%)$ e Carbono ( $\mathrm{C}=34,66 \%)$ presentes no carvão ativado do mesocarpo enponjoso da castanha de caju (Anacardium occidentale), identificados na Espectroscopia por Energia Dispersiva (EDS). Com efeito, para Linhares, Marcílio e Melo (2016), o oxigênio em elevadas concentrações pode obstruir os poros, comprometendo a área especifica do material. Além disso, o equipamento utilizado para mensuração da $S_{B E T}$ possui limitações para análise de amostras com características microporosas, dificultando ainda mais a análise real da área superficial do carvão utilizado nesta pesquisa.

\subsection{Adsorção}

\subsubsection{Análise de concentração inicial}

Quanto a análise da concentração inicial, os dados analisados indicam que a capacidade de adsorção $\left(\mathrm{Q}_{e}, \mathrm{mg} / \mathrm{g}^{-1}\right)$ e a eficiência de remoção do corante verde malaquita (Remoção \%) demonstram tendências invrsamente proporcionais, conforme aumenta a concentração (Figura 9). 
Figura 9 - Efeito da concentração inicial da solução de corante Verde Malaquita.

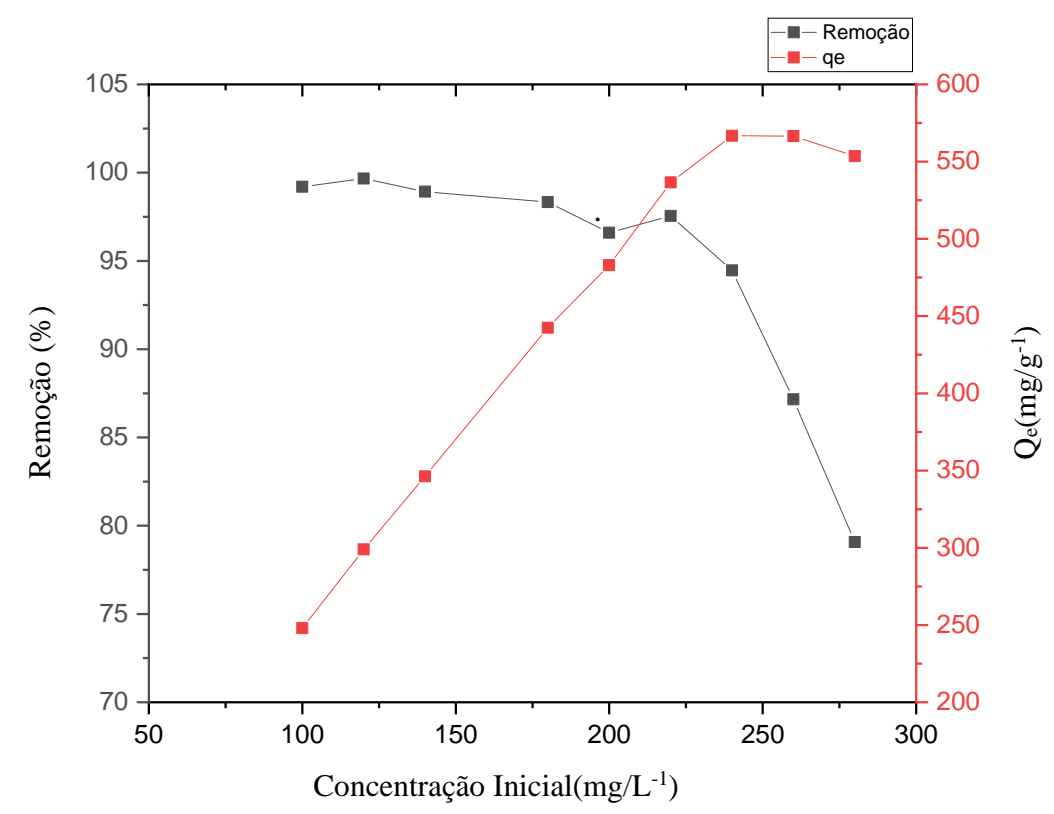

Fonte: Autores (2021).

Os resultados indicam remoção de 99,2\%, com capacidade de adsorção em Q $e=248 \mathrm{mg}$. $\mathrm{g}^{-1}$, na concentração $100 \mathrm{mg} / \mathrm{L}^{-}$ ${ }^{1}$. Além desse, tabem indicou 99,6\% e adsorção em Qe $=248 \mathrm{mg} \cdot \mathrm{g}^{-1}$ para $120 \mathrm{mg} / \mathrm{L}^{-1}$ em corante Verde Malaquita. Entretanto, deste ponto em diante esta porcentagem decresce, de 99,6\% para 79,07\%. Por outro lado, a capacidade de adsorção aumenta, de $\mathrm{Q}_{e}=248 \mathrm{mg} / \mathrm{g}^{-1}$ para $\mathrm{Qe}=553,5 \mathrm{mg} / \mathrm{g}^{-1}$. Nota-se que isto ocorre à medida em que a concentração de corante se eleva.

Para efeito de comparação, Azevedo (2015), a remoção do corante amarelo básico 02, decresce de 98,9\% com 100 $\mathrm{mg} / \mathrm{L}^{-1}$ até $96 \%$ para a concentração de $170 \mathrm{mg} / \mathrm{L}^{-1}$. A partir deste ponto, o percentual de remoção decresce até $83 \%$ para uma concentração inicial de $300 \mathrm{mg} / \mathrm{L}^{-1}$.

Segundo Brandão, Queiroz e Silva (2020), isto ocorre, pois, com o aumento da concentração inicial do corante, haveria mais espécies distribuídas na superfície do adsorvente, o que contribui para uma maior formação de ligações químicas na superfície No entanto, a diminuição acontece pela competição entre as moléculas de adsorvato para agregação nos sítios do adsorvente nas concentrações finais (Figura 10).

Figura 10 - Remoção do corante verde Malaquita.

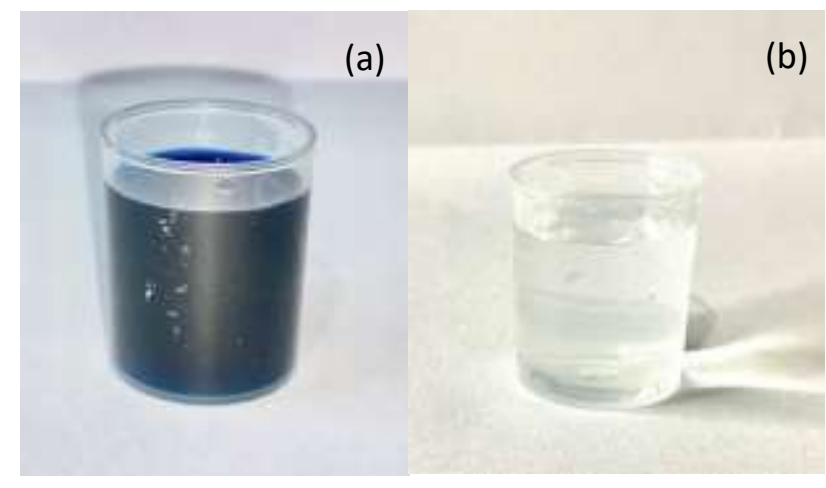




\subsection{Equilíbrio de adsorção}

\subsubsection{Isoterma de Langmuir}

Os dados obtidos e analisados, quanto ao equilíbrio de adsorção do corante Verde Malaquita, indicaram que o modelo matemático melhor ajustado aos dados experimentais foi de Langmuir, indicando a ocorrência de adsorção em monocamada (Figura 11). Nestas perspectivas, este modelo apresenta maiores taxas para coeficiente de determinação $\left(\mathbf{R}^{2} a d j=0,8487\right)$, e capacidade máxima de adsorção $\left(\mathrm{Q}_{\max }=573,83 \mathrm{mg} / \mathrm{g}^{-1}\right)$. Além disso, está isoterma apresenta características pertencentes ao do tipo "L". Ainda neste sentido, os dados indicaram parâmetro de equilíbrio favorável ( $R L=0,0013)$, com valor entre $0<\mathrm{R} L<1$ (Tabela 2).

Figura 11- Dados de equilíbrio de adsorção do corante Verde Malaquita para o modelo de Langmuir.

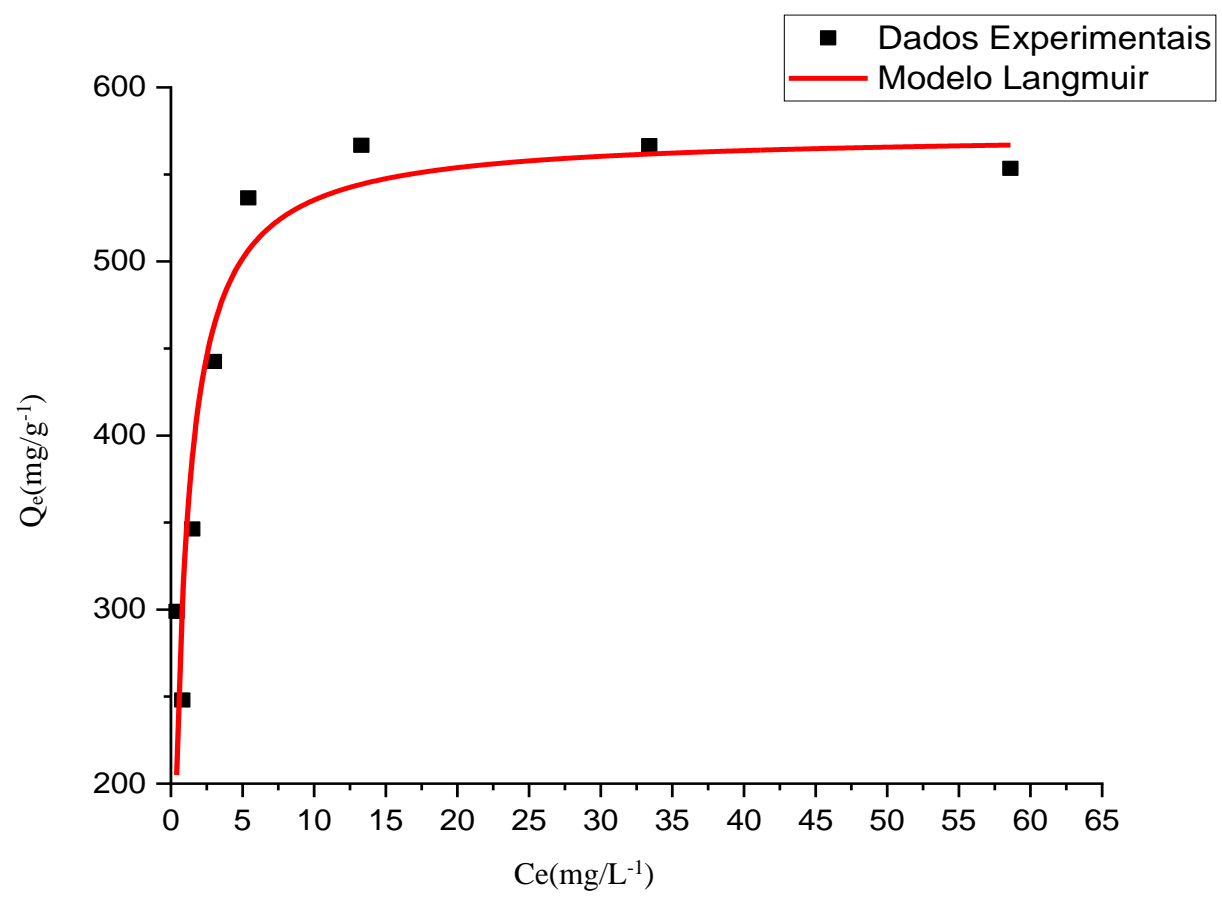

Fonte: Autores (2021).

Tabela 2 - Valores dos parâmetros para equilíbrio segundo a isoterma de Langmuir.

\begin{tabular}{ccc}
\hline \multicolumn{3}{c}{ Isoterma Langmuir } \\
\hline $\boldsymbol{q}_{\boldsymbol{e}(\boldsymbol{m a x})}$ & $\boldsymbol{R l}$ & $\mathbf{R}^{2} a d j$ \\
$\left(\mathbf{m g} / \boldsymbol{g}^{-\mathbf{1}}\right)$ & & \\
\hline $\mathbf{5 7 3 , 8 3}$ & 0,0013 & 0,8487
\end{tabular}

Fonte: Autores (2021).

Pesquisa similar, realizada por Oliveira, Silva e Viana (2013), com carvão ativado a partir do mesocarpo de coco verde na adsorção do corante Azul de Metileno, apresentaram isoterma do tipo "L", indicando que os sítios ativos de adsorção diminuem sua disponibilidade à medida que a concentração da solução se eleva. 
Quanto aos resultados obtidos para os parâmetros de equilíbrio e capacidade máxima de adsorção, é importante destsacar que estudo, por Tang, e Zaini (2020), sobre a adsorção de corante Verde Malaquita, com carvão ativado produzido a partir de pellets (Biomassas), obtiveram resultados satisfatórios em relação ao fator de equilíbrio ( $\mathrm{R} l=0,2-0,8)$. Com efeito, removendo taxas de 41,5-395 mg/ $\mathrm{g}^{-1}$ de corante com eficácia. Estes resultados confirmam que, conforme o valor $\mathrm{R} L$ se aproxima de zero, mais favorável é o processo de adsorção. Isto justifica o aumento na capacidade máxima de adsorção $\left(\mathrm{Q}_{\max }=573,83 \mathrm{mg} /\right.$ $\left.\mathrm{g}^{-1}\right)$ e corraboram com esta pesquisa.

\subsubsection{Isoterma Freundlich}

Quando a isoterma de Freundlich, os dados obtidos e analisados indicaram que houve ajuste às características experimentais no processo de adsorção, devido a menor taxa para coeficiente de determinação ( $\left.\mathbf{R}_{a d j}^{2}=0,7342\right)$ (Figura 12). Neste sentido, apresenta baixa na constante de Freundlich, relacionada a capacidade de adsorção $\left(\mathrm{K} f=351,03 \mathrm{mg} \cdot \mathrm{g}^{-1}\right)$. Além disso, essa isoterma também apresenta características pertencentes ao tipo "L", segundo a classificação de Giles et al., (1974). Os dados indicam parâmetro favorável $(n=7,192)$, com valor entre $1<n<10$ (Tabela 3).

Figura 12 - Dados de equilíbrio de adsorção do corante Verde Malaquita para modelo de Freundlich.

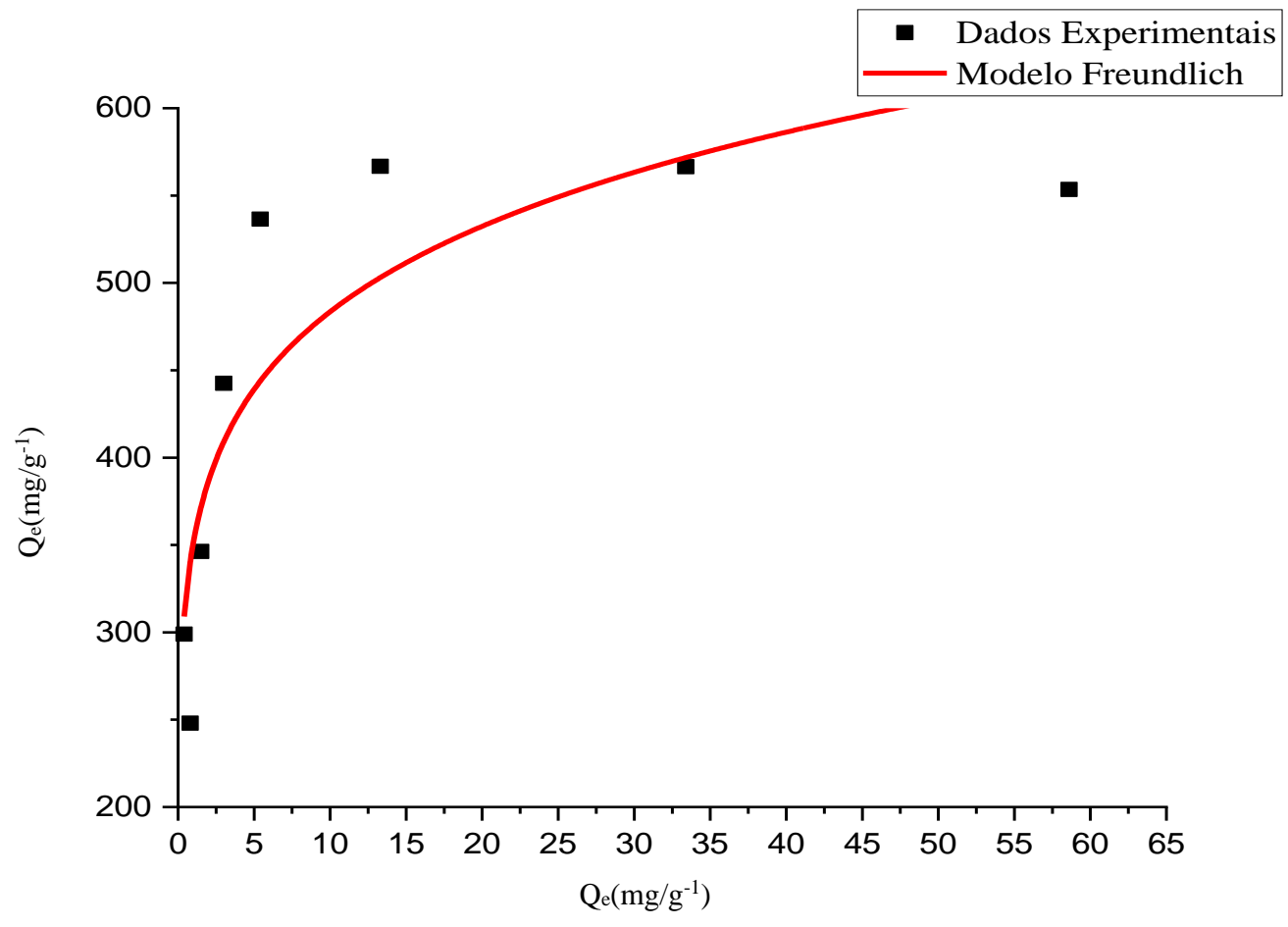

Fonte: Autores (2021).

Tabela 3 - Valores dos parâmetros para equilíbrio segundo a isoterma de Freundlich.

\begin{tabular}{ccc}
\hline \multicolumn{3}{c}{ Isoterma Freundlich } \\
\hline $\boldsymbol{K} \boldsymbol{f}$ & $\boldsymbol{n}$ & $\mathbf{R}^{\mathbf{2}}$ adj \\
$\left(\mathbf{m g} / \boldsymbol{g}^{-\mathbf{1}}\right)$ & & \\
\hline $\mathbf{3 5 1 , 0 3}$ & 7,192 & 0,7342 \\
\hline
\end{tabular}

Fonte: Autores (2021). 
Dessa maneira, para remoção de Verde Malaquita por carvão ativado, preparado a partir do epicarpo de mamona (Ricinus communis), por Santhi, Manonmani e Smith (2010), indicou coeficiente de determinação $\left(\mathrm{R}^{2} a d j=0,982\right)$ menor em relação ao modelo de Langmuir $\left(\mathrm{R}^{2} a d j=0,987\right)$, consequentemente ajustou-se a Langmuir, com prevalência de monocamadas.

O modelo de Freundlich não se ajustou aos dados experimentais, devido apresentar menor valor no coeficiente de determinação ( $\left.\mathbf{R}_{a d j}{ }_{a d j}=0,7342\right)$, em relação ao modelo de Langmuir $\left(\mathbf{R}^{2}{ }_{a d j}=0,8487\right)$. Em virtude disso, os dados indicam formação de monocamada no carvão ativado da casca da castanha de caju (Anacardium occidentale). Segundo Zhang et al. (2017), estes resultados concluem que o processo de adsorção ocorre em superfície homogênea com a superfície do adsorvente uniforme e com todos os sítios ativos de adsorção possuindo a mesma energia.

Quanto ao parâmetro de Freundlich ou fator empírico $(n)$, outros auejtores evidenciam valores favoráveis $(1<n<10)$ para adsorção de corantes, como Aljeboree, Alshirifi e Alkaim (2017). Estes, em estudo de adsorção de corantes têxteis em carvão ativado com casca de coco (Nucifera), indicaram para corante amarelo direto $(n=0.0403)$, e Maxilon azul $(n=0.0521)$.

\subsection{Cinética de adsorção}

\subsubsection{Pseudo-primeira Ordem e Pseudo-segunda Ordem}

A análise dos dados obtidos, para estudar a cinética de adsorção do corante Verde Malaquita, indicaram que o pseudosegunda ordem (Figura 13) evidencia maior valor para coeficiente de determinação ( $R^{2}$ adj $\left.=0,94161\right)$ em relação ao piseudoPrimeira ordem. Para o pseudo-segunda ordem, a capacidade máxima de adsorção calculada $\left(\mathrm{Q}_{e, \text { cal. }}=258,95 \mathrm{mg} / \mathrm{g}^{-1}\right)$ se aproxima dos dados referentes à capacidade máxima de adsorção experimental $\left(\mathrm{Q}_{e, \text { exp }}=248,75 \mathrm{mg} / \mathrm{g}^{-1}\right)$.

Figura 13 - Dados de cinética de adsorção do corante Verde Malaquita.

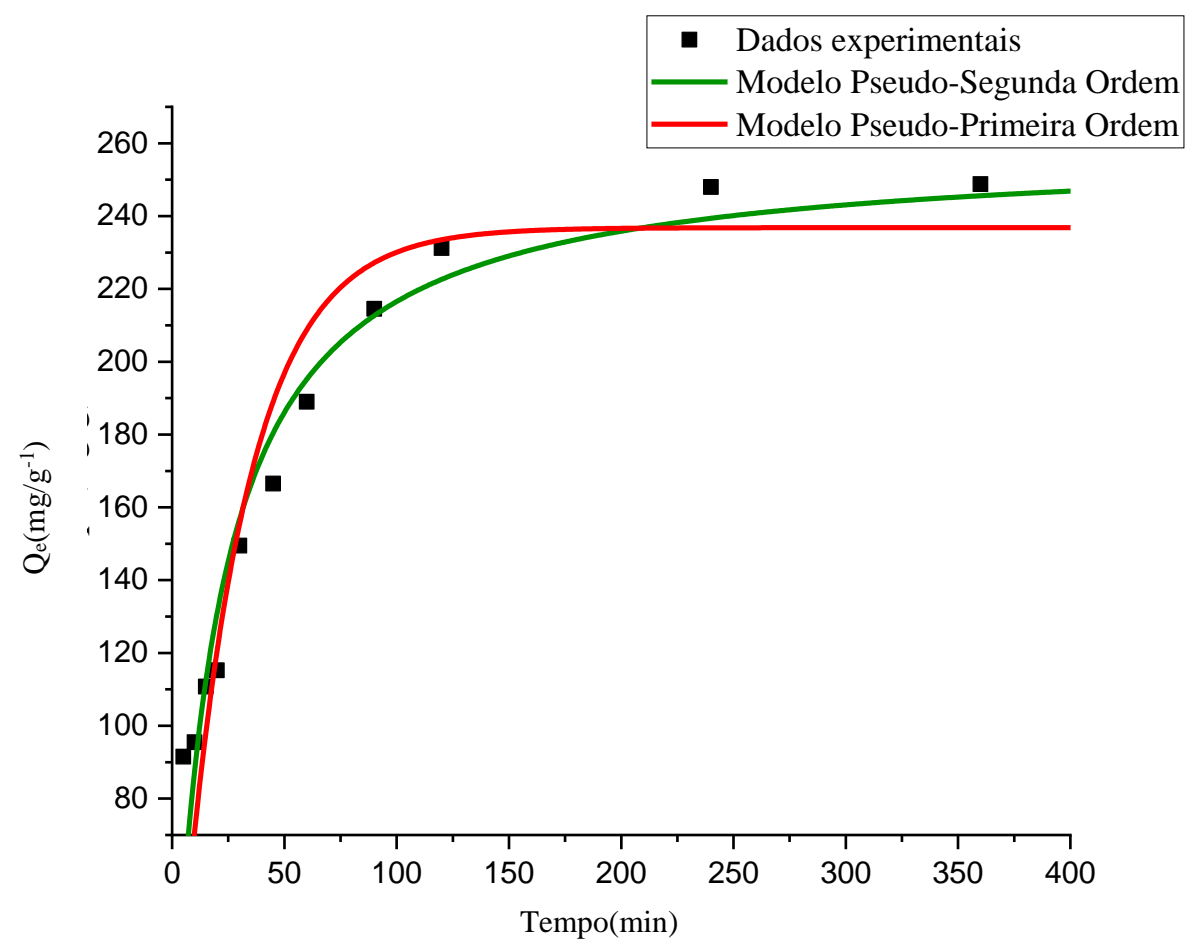

Fonte: Autores (2021).

Por outro lado, o modelo matemático pseudo-primeira ordem não se ajustaram satisfatoriamente aos dados experimentais no processo de adsorção, devido o menor taxa para coeficiente de determinação $\left(\mathrm{R}^{2} a d j=0,8687\right)$. Para este modelo, 
a capacidade máxima de adsorção calculada $\left(\mathrm{Q}_{e, \text { cal. }}=236,82 \mathrm{mg} / \mathrm{g}^{-1}\right)$ novamente se aproxima da capacidade de adsorção experimental $\left(\mathrm{Q}_{e, \exp }=248,75 \mathrm{mg} / \mathrm{g}^{-1}\right)$. No entanto, não tão próximo quanto para o modelo pseudo-segunda ordem (Tabela 4).

Tabela 4 - Parâmetros de cinética de adsorção do corante Verde Malaquita.

\begin{tabular}{|c|c|c|c|c|c|c|}
\hline \multirow[b]{2}{*}{$\begin{array}{l}q_{e(e x p)} \\
(\mathrm{mg} . g)\end{array}$} & \multicolumn{3}{|c|}{ Modelo pseudo-primeira ordem } & \multicolumn{3}{|c|}{ Modelo pseudo-segunda ordem } \\
\hline & $\begin{array}{c}\boldsymbol{q}_{e(c a l)} \\
\left(\mathbf{m g} / g^{-1}\right)\end{array}$ & $\begin{array}{c}k_{1} \\
\left(\min ^{-1}\right)\end{array}$ & $\mathbf{R}^{2}$ & $\begin{array}{c}q_{e(c a l)} \\
\left(\mathbf{m g} / g^{-1}\right)\end{array}$ & $\begin{array}{c}k_{2} \\
\left(g \cdot m g^{-1} \cdot \min ^{-1}\right)\end{array}$ & $\mathbf{R}^{2}$ \\
\hline 248,75 & 232,84536 & 0,03714 & 0,85235 & 260,64369 & 1,92138 & 0,93225 \\
\hline
\end{tabular}

Fonte: Autores (2021).

Sharma et al. (2019), com carvão ativado produzido com pinheiros (Pinus roxburghiicone), para adsorção do corante verde malaquita, indicando adequação ao modelo pseudo-segunda ordem, com coeficiente de determinação $\left(\mathbf{R}^{2}{ }_{a d j}=0,980\right)$; já pseudo-primeira ordem evidenciou coeficiente de determinação menor $\left(\mathrm{R}^{2}{ }_{a d j}=0.826\right)$. Com efeito, concluíram que os ajustes ao modelo cinético de pseudo-segunda ordem significam predominância no processo de adsorção de natureza química (quimissorção).

Além disso, os dados obtidos e analisados indicam um pico de adsorção nos primeiros 140 minutos, decrescendo até chegar em equilíbrio. Segundo Georgin et al. (2015), com carvão ativado produzido a partir da casca do amendoim convencional (Arachis hypogaea), esse pico inicial ocorre, pois, quanto maior as concentrações de corante nos minutos iniciais, mais sítios de adsorção são ocupados no adsorvente.

Quanto aos valores de capacidade máxima de adsorção, para Naushad et al. (2019), quanto mais próximo a capacidade máxima de adsorção calculada $\left(\mathrm{Q}_{e, c a l}\right)$, em relação a experimental $\left(\mathrm{Q}_{e, \text { exp }}\right)$, mais representativo será o modelo cinético dos dados experimentais.

\subsubsection{Difusão intapartícula}

A análise dos dados obtidos, no que diz respeito ao corante Verde Malaquita, indicou que dentre os modelos PseudoPrimeira ordem, Pseudo-Segunda Ordem, e Difusão intrapartícula, obteve-se um ajuste satisfatório para o modelo cinético de Difusão Intrapartícula, com elevada taxa no coeficiente de determinação $\left(\mathrm{R}^{2}\right.$ adj $\left.=0,9966\right)$, (Figura 14). Neste sentido, o modelo indicou três regiões distintas: (a) Difusão do corante Verde Malaquita para a superfície externa do carvão ativado; (b) Difusão intrapartícula; (c) Alcance do equilíbrio dinâmico. Além disso, os dados indicam valor satisfatório quanto a constante de espessura da camada limite $\left(C=69,13 \mathrm{mg} / \mathrm{g}^{-1}\right)$. 
Figura 14 - cinética de adsorção do corante Verde Malaquita para o modelo difusão intrapartícula.

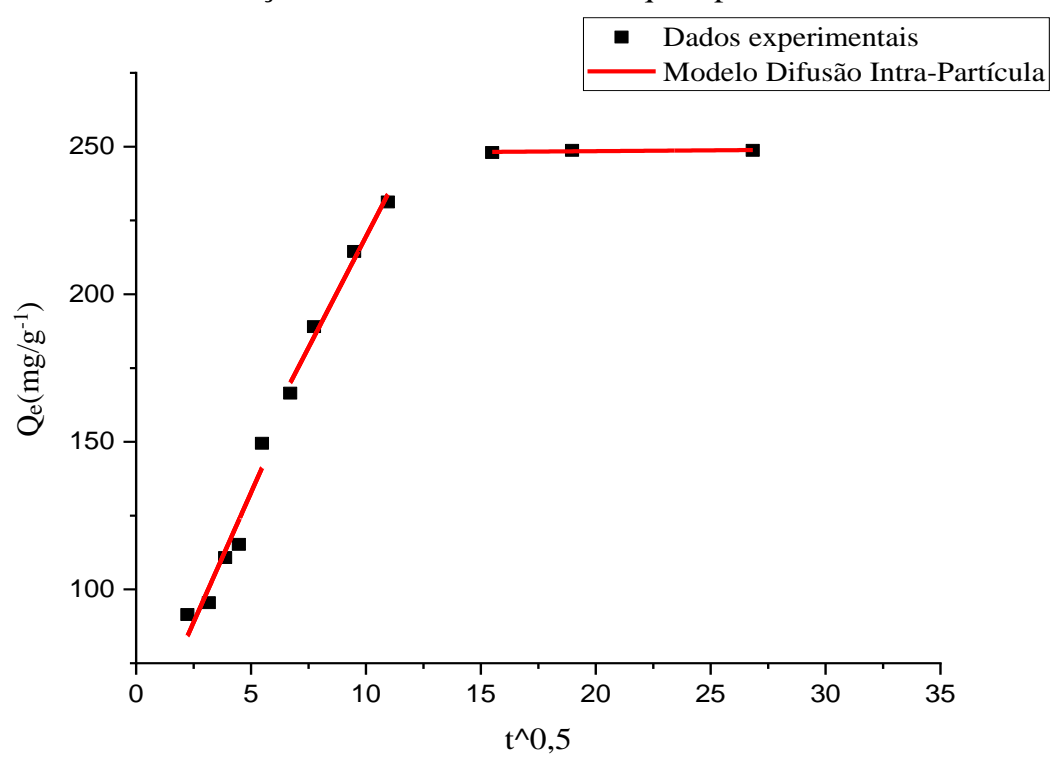

Fonte: Autores (2021).

Os dados para constante de espessura da camada limite (C) são satisfatórios. Segundo Morais et al. (2019), este valor, fornece uma aproximação da espessura da camada limite, com efeito diretamente proporcional, ou seja, quanto maior a taxa para constante $(C)$, mais elevado será o efeito da camada limite.

Estudo efetuado por Idohou et al. (2020), sobre estudo da cinética de adsorção em Azul de Metileno, com carvão ativado produzido com sementes de mamão (Carica papaya), obtiveram resultados similares para o coeficiente de determinação ( $\mathbf{R}^{2}{ }_{a d j}$ $=0,996)$, porém se diferem em relação à constante de espessura da camada limite $(C=20.73 \mathrm{mg} / \mathrm{g})$. Isso pode estar relacionado as diferenças nas concentrações do adsorvato, bem como a quantidade de adsorvente utilizado em cada estudo.

\section{Conclusão}

Portanto, observou-se a ocorrência de uma estrutura compacta com predominância de microporos, assim como uma baixa área superficial, devido ao excesso de Oxigênio (O). Todavia, o carvão ativado do mesocarpo da castanha de caju (Anacardium Occidentale) demonstrou eficácia, no processo de adsorção do corante verde malaquita. Isto é atribuído a presença de grupos orgânicos funcionais presente no solido estudado. Com efeito, adsorção seguiu um equilíbrio em modelo de adsorção de Langmuir e cinética para Difusão intrapartícula, consequentemente, processo em superfície mais homogênea.

Desse modo, é importante a continuidade dessa pesquisa em efluentes de origem inorgânica, como metais pesados e dentre outros, recomenda-se que em futuros trabalhos, possam refazer a análise superficial específica para ambos os carvões em equipamento capaz de identificar microporosidade.

\section{Agradecimentos}

Agradeço primeiro a Deus por ter me mantido na trilha certa durante este projeto de pesquisa com saúde e forças para chegar até o final. Sou grato à minha família pelo apoio que sempre me deram durante toda a minha vida. Agradeço também minha amiga e também autora, Ana Vitoria da Silva Barral por todo apoio e dedicação.

Deixo um agradecimento especial ao meu orientador Luiz Eduardo Chaves Azevedo, pelo incentivo e pela dedicação do seu tempo ao meu projeto de pesquisa. Também quero agradecer à Universidade do Estado do Pará (UEPA), e a todos os professores do meu curso pela elevada qualidade do ensino oferecido. Agradecer também ao meu coorientador João Rodrigo, e, 
aos amigos Fernando e Gesivaldo, Leticia Picanço.

\section{Referências}

Albuquerque, M. M. K., dos Santos Oliveira, C. B., Veras, M. D. A., Araújo, B. Q., Dantas, C., Chaves, M. H., \& Vieira, E. C. (2019). Application of multivariate optimization for the selective extraction of phenolic compounds in cashew nuts (Anacardium occidentale L.). Talanta, 205, 120100.

Alencar, N. S., Gonçalves, J. F., de Oliveira, E. A. F., Lucena, T. C., Sousa, R. M. (2018). Produção da Castanha de Caju nas microrregiões do Ceará no período de 1993 a 2016. Revista Eletrônica Competências Digitais para Agricultura Familiar, 4(1), 103-116.

Aljeboree, A. M., Alshirifi, A. N., Alkaim, A. F. (2017). Kinetics and equilibrium study for the adsorption of textile dyes on coconut shell activated carbon. Arabian journal of chemistry, 10, S3381-S3393.

Almeida, C. F. (2015). Produção de carvão ativado quimicamente a partir da palmácea mauritia flexuosa e o estudo de suas propriedades adsortivas. (Mestrado em Química, Faculdade de Ciências Exatas e Tecnologia, Universidade Federal da Grande Dourados).

Almeida, C. F., Andrade, R. C., Oliveira, G. F., Suegama, P. H, Arruda, E. J., Texeira, J. A. Carvalho, C. T. (2017). Study of porosity and surface groups of activated carbons produced from alternative and renewable biomass: buriti petiole. Orbital, 18-26.

Almeida, E. S. C. Pinto, B. C. Lima, A. S, Oliveira, M. A., da Silva Bezerra, A. C., Souza, T. S. F., \& Machado, A. R. T. (2017). Equilíbrio de adsorção do corante rodamina B em carvão ativado obtido dos resíduos do coco verde. The Journal of Engineering and Exact Sciences, 3(8), 1051-1058.

Andrade, R. C., de Almeida, C. F., Suegama, P. H., de Arruda, E. J., Arroyo, P. A., \& de Carvalho, C. T. (2015). Buriti palm stem as a potential renewable source for activated carbon production. Environmental Technology \& Innovation, 3, 28-34.

Araújo, C. S., Almeida, I. L., Rezende, H. C., Marcionilio, S. M., Léon, J. J., \& de Matos, T. N. (2018). Elucidation of mechanism involved in adsorption of Pb (II) onto lobeira fruit (Solanum lycocarpum) using Langmuir, Freundlich and Temkin isotherms. Microchemical Journal, 137, $348-354$.

Azevedo, L. E. C. D. (2015). Adsorção de corantes básicos empregados na indústria têxtil por argila: cinética e perfil de equílibrio. (Mestrado em Engenharia Química, Universidade Federal do Pará).

Bankole, P. O., Adekunle, A. A., Obidi, O. F., Chandanshive, V. V., \& Govindwar, S. P. (2018). Biodegradação e desintoxicação do corante Scarlet RR por um fungo filamentoso isolado recentemente, Peyronellaea prosopidis. Sustainable Environment Research, 28 (5), $214-222$.

Beltrame, T. F., Beltrame, A. F., Lhamby, A., \& Pires, V. K. (2016). Efluentes, resíduos sólidos e educação ambiental: Uma discussão sobre o tema. Revista Eletrônica em Gestão, Educação e Tecnologia Ambiental, 20(1), 283-294.

Bezerra, J. K. A., Lopes, R. P. F., Barros Neto, E. L., Souza, M. A. S. B., \& Nunes, A. O. (2019). Remoção de cobre (II) em solução aquosa por adsorção usando carvão ativado produzido a partir do lodo doméstico. Revista Virtual de Química, 11(6).

Boukhemkhem, A., \& Rida, K. (2017). Improvement adsorption capacity of methylene blue onto modified Tamazert kaolin. Adsorption Science \& Technology, 35(9-10), 753-773.

Brandão, A. C. T., Queiroz, V., \& Silva, R. G. C. (2020). Síntese e caracterização de carvão ativado quimicamente com H3Po4 e NaOH à partir da casca de pequi (Caryocar brasiliense). Brazilian Journal of Development, 6(8), 60945-60962.

Brandão, P. C., Souza, T. C., Ferreira, C. A., Hori, C. E., \& Romanielo, L. L. (2010). Removal of petroleum hydrocarbons from aqueous solution using sugarcane bagasse as adsorbent. Journal of Hazardous Materials, 175(1-3), 1106-1112.

Brunauer, S., Emmett, P. H., \& Teller, E. (1938). Adsorption of gases in multimolecular layers. Journal of the American chemical society, 60(2), 309-319.

Campos, NF, Barbosa, CM, Rodríguez-Díaz, JM, \& Duarte, MM (2018). Remoção de ácidos naftênicos usando carvão ativado: estudos cinéticos e de equilíbrio. Adsorption Science \& Technology, 36 (7-8), 1405-1421.

Cardoso, C. K. M., de Santana, R. S. G., da Silva, V. L., Meirelles, A. C. L. E., Mattedi, S., Moreira, Í. T. A., \& Lobato, A. K. D. C. L. (2020). Estudo cinético e de equilíbrio de adsorção de petróleo utilizando fibras de coco pré-tratadas. Research, Society and Development, 9(7), e523974413-e523974413.

Castro, J. P., Nobre, J. R. C., Bianchi, M. L., Trugilho, P. F., Napoli, A., Chiou, B. S., \& Tonoli, G. H. (2019). Activated carbons prepared by physical activation from different pretreatments of amazon piassava fibers. Journal of Natural Fibers, 16(7), 961-976.

Coelho, E. R. C., \& Rozário, A. D. (2019). Remoção do 2, 4-D em amostras de águas pela adsorção em leitos fixos de carvão ativado granular em escala reduzida. Engenharia Sanitaria e Ambiental, 24(3), 453-462.

Coelho, G. F. (2014). Utilização da casca da castanha de caju Anarcadium occidentale L. como biossorvente de metais. (Mestrado em Agronomia, Universidade Estadual do Oeste do Paraná).

Costa, P. D., Furmanski, L. M., \& Dominguini, L. (2015). Produção, caracterização e aplicação de carvão ativado de casca de nozes para adsorção de azul de metileno. Revista virtual de química, 7(4), 1272-1285.

Crini, G., \& Lichtfouse, E. (2019). Advantages and disadvantages of techniques used for wastewater treatment. Environmental Chemistry Letters, 17(1), 145155 .

Du, H., Cheng, J., Wang, M., Tian, M., Yang, X., \& Wang, Q. (2020). Red dye extracted sappan wood waste derived activated carbons characterization and dye adsorption properties. Diamond and Related Materials, 102, 107646. 
Fernandes, H. D., Carvalho, C. D. F., Paula, C. C. P. D., Azevedo, L. S. D., \& Gonçalves, S. M. D. (2019). Reciclagem de éter-aminas, utilizadas na flotação de minério de ferro, por meio da adsorção. Engenharia Sanitaria e Ambiental, 24(2), 251-260.

Georgin, J., Dotto, G. L., Mazutti, M. A., \& Foletto, E. L. (2016). Preparation of activated carbon from peanut shell by conventional pyrolysis and microwave irradiation-pyrolysis to remove organic dyes from aqueous solutions. Journal of Environmental Chemical Engineering, 4(1), 266-275.

Giles, C. H., Smith, D., \& Huitson, A. (1974). A general treatment and classification of the solute adsorption isotherm. I. Theoretical. Journal of colloid and interface science, $47(3), 755-765$.

GOMES, J. N. (2015). Estudo da adsorção de corantes por meio do Carvão ativado de osso de boi.

Guedes, A. F., Tavares, L. N., Marques, M. N. D. N., Moura, S. P., \& Sousa, M. N. A. D. (2017). Tratamento da água na prevenção de doenças de veiculação hídrica. Journal of medicine and Helth Promotion, 2(1), 452-461.

Gupta, H., \& Gupta, B. (2016). Adsorption of polycyclic aromatic hydrocarbons on banana peel activated carbon. Desalination and Water Treatment, 57(20), 9498-9509.

Ho, Y. S. (2006). Review of second-order models for adsorption systems. Journal of hazardous materials, 136(3), 681-689.

Ho, Y. S., \& McKay, G. (1999). Pseudo-second order model for sorption processes. Process biochemistry, 34(5), 451-465.

Idohou, E. A., Fatombi, J. K., Osseni, S. A., Agani, I., Neumeyer, D., Verelst, M., \& Aminou, T. (2020). Preparation of activated carbon/chitosan/Carica papaya seeds composite for efficient adsorption of cationic dye from aqueous solution. Surfaces and Interfaces, 21, 100741.

Kawahigashi, F., Mendes, M. B., Assunção Júnior, V. G. D., Gomes, V. H., Fernandes, F., Hirooka, E. Y., \& Kuroda, E. K. (2014). Pós-tratamento de lixiviado de aterro sanitário com carvão ativado. Engenharia sanitária e ambiental, 19(3), 235-244.

Lermen, A. M. (2017). Absorção do corante azul de metileno em carvão ativado produzido a partir da pinha de pinus taeda. (bacharelado em Engenharia Ambiental e Sanitária, Universidade Federal da Fronteira Sul).

Li, X. R., Jiang, Y. H., Wang, P. Z., Mo, Y., Li, Z. J., Yu, R. J., Chen, Y. (2020). Effect of the oxygen functional groups of activated carbon on its electrochemical performance for supercapacitors. New Carbon Materials, 35(3), 232-243.

Liang, J., Ning, X. A., Sun, J., Song, J., Lu, J., Cai, H., Hong, Y. (2018). Toxicity evaluation of textile dyeing effluent and its possible relationship with chemical oxygen demand. Ecotoxicology and environmental safety, 166, 56-62.

Lima, D. R. D. (2017). Avaliação do desempenho anticorrosivo do revestimento de polibenzoxazina sintetizada a partir do líquido da castanha de caju. (Mestrado em Engenharia e Ciência de Materiais, Universidade Federal do Ceará).

Limousin, G., Gaudet, J. P., Charlet, L., Szenknect, S., Barthes, V., Krimissa, M. (2007). Sorption isotherms: A review on physical bases, modeling and measurement. Applied geochemistry, 22(2), 249-275.

Linhares, F. A., Marcílio, N. R., Melo, P. J. (2016). Estudo da produção de carvão ativado a partir do resíduo de casca da acácia negra com e sem ativação química. Scientia cum Industria, 4(2), 74-79.

Ludwig, B. C. (2018). Sistema hibrido com eletro-fenton e adsorção para tratamento de águas residuárias de tingimento de pedras semipreciosas. (Mestrado em Engenharia Civil e Ambiental, Universidade de Passo Fundo).

Maneerung, T., Liew, J., Dai, Y., Kawi, S., Chong, C., \& Wang, C. H. (2016). Activated carbon derived from carbon residue from biomass gasification and its application for dye adsorption: kinetics, isotherms and thermodynamic studies. Bioresource technology, 200, 350-359.

Mazzetto, S. E., Lomonaco, D., \& Mele, G. (2009). Óleo da castanha de caju: oportunidades e desafios no contexto do desenvolvimento e sustentabilidade industrial. Química Nova, 32(3), 732-741.

Metcalf, L., \& Eddy, H. P. (2015). Tratamento de efluentes e recuperação de recursos. McGraw Hill Brasil.

Morais, R. M., Santana, G. M., Lelis, R. C. C., Schueler, M. V. E., Morbeck, F. L., \& Paes, J. B. (2019). Produção de carvão ativado a partir de Eucalyptus dunnii para adsorção de corante azul de metileno. Revista Ciência da Madeira (Brazilian Journal of Wood Science), 10(1).

Motta Sobrinho, M. A. D., Paulino, P. M., \& Oliveira, D. E. B. D. (2019). Pós-tratamento de lixiviados coagulados por adsorção em resíduos da ostreicultura. Engenharia Sanitaria e Ambiental, 24(5), 897-907.

Müller, L. C., Alves, A. A. D. A., Mondardo, R. I., \& Sens, M. L. (2019). Adsorção do azul de metileno em serragem de Pinus elliottii (pinus) e Drepanostachyum falcatum (bambu). Engenharia Sanitaria e Ambiental, 24(4), 687-695.

Naushad, M., Alqadami, A. A., AlOthman, Z. A., Alsohaimi, I. H., Algamdi, M. S., \& Aldawsari, A. M. (2019). Adsorption kinetics, isotherm and reusability studies for the removal of cationic dye from aqueous medium using arginine modified activated carbon. Journal of Molecular Liquids, $293,111442$.

Oliveira, G. F. D. (2016). Produção de carvão ativado a partir do pecíolo do babaçu. (Dissertação mestrado, Faculdade de Ciências Exatas e Tecnologia da Universidade Federal da Grande).

Oliveira, R. D. S., Borges, M. F., Vieira, A. T., Henrique, M. A., Ribeiro, E. A. M., Bezerra, F. A., \& Ruggiero, R. (2018). Adsorção de contaminantes do biodiesel por fibras de bagaço modificadas na superfície. Química Nova, 41(2), 121-128.

Oliveira, S. P., Silva, W. L. L. D., \& Viana, R. R. (2013). Avaliação da capacidade de adsorção do corante azul de metileno em soluçãoes aquosas em caulinita natural e intercalada com acetato de potássio. Cerâmica, 59(350), 338-344. 
Patias, S. G. O., Sávio, J., Costelli, M. C., da Silva, A., Cancelier, A., \& Lopes, T. J. (2015). Obtenção de carvão adsorvente oriundo da casca de pequi (Caryocar brasiliense) e sua aplicação no tratamento de efluentes da indústria têxtil através do processo de adsorção. Rev. Eletrônica em Gestão, Educ. e Tecnol. Ambient, 19, 1482-1492.

Pereira, A. S., Shitsuka, D. M., Parreira, F. B., \& Shitsuka, R. (2018). Metodologia da pesquisa científica. UFSM.

Peláez-Cid, A. A., Herrera-González, A. M., Salazar-Villanueva, M., \& Bautista-Hernández, A. (2016). Elimination of textile dyes using activated carbons prepared from vegetable residues and their characterization. Journal of environmental management, 181, 269-278.

Pizato, E., Lopes, A. C., Rocha, R. D. C., Barbosa, A. D. M., \& Cunha, M. A. A. D. (2017). Caracterização de efluente têxtil e avaliação da capacidade de remoção de cor utilizando o fungo Lasiodiplodia theobromae MMPI. Engenharia Sanitaria e Ambiental, 22(5), $1027-1035$.

Popa, N., \& Visa, M. (2017). The synthesis, activation and characterization of charcoal powder for the removal of methylene blue and cadmium from wastewater. Advanced Powder Technology, 28(8), 1866-1876.

Pott, C. M., \& Estrela, C. C. (2017). Histórico ambiental: desastres ambientais e o despertar de um novo pensamento. Estudos avançados, 31(89), 271-283.

Prodanov, C. C., \& de Freitas, E. C. (2013). Metodologia do trabalho científico: métodos e técnicas da pesquisa e do trabalho acadêmico-2a Edição. Editora Feevale.

Ramos, M. D. N., Cláudio, C. C., Rezende, P. H. V., Cabral, L. P., Santos, L. A., Costa, G. G., \& Aguiar, A. (2020). Análise crítica das características de efluentes industriais do setor têxtil no Brasil. Revista Virtual de Química, 12(4).

Ribas, M. C. (2016). Remoção de corantes têxteis pelo processo de adsorção utilizando carvão ativado produzido a partir de subprodutos agroindustriais: estudos em batelada e coluna de leito fixo. (Tese de Doutorado, Universidade Federal do Rio Grande do Sul).

Ries, L. A. S., \& da Silveira, J. H. (2019). Remoção de Cr (VI) por adsorção empregando carvão ativado comercial e carvão vegetal produzido a partir da casca de arroz. Brazilian Journal of Development, 5(6), 6477-6494.

Rimoli, M. F. D. S., Nogueira, R. M., Ferrarini, S. R., Castro, P. M. D., \& Pires, E. M. (2019). Preparation and characterization of carbon from the fruit of Brazil nut tree activated by physical process. Revista Árvore, 43(2).

Rocha, L. S. D. (2017). Estudo da remoção de microcistinas por adsorção em nanotubos de titanato de hidrogênio a partir de uma substância modelo (Master's thesis, Universidade Tecnológica Federal do Paraná).

Sales, P. F., Bertoli, A. C., Pinto, F. M., \& Magriotis, Z. M. (2015). Produção, caracterização e aplicação do carvão ativado obtido a partir do sabugo de milho: a busca pelo reaproveitamento de um resíduo agroindustrial. Revista Virtual de Química, 7(4), 1174-1188.

Santhi, T., Manonmani, S., \& Smitha, T. (2010). Removal of malachite green from aqueous solution by activated carbon prepared from the epicarp of Ricinus communis by adsorption. Journal of hazardous materials, 179(1-3), 178-186.

SANTOS, G. C. D. (2016). Adsorção de derivados de petróleo com vermiculita organofilizada. (Mestrado em Engenharia Química, Universidade Federal de Campinas).

Schimmel, D. (2008). Adsorção dos corantes reativos azul 5G e azul turquesa QG em carvão ativado comercial. (Mestrado em Engenharia Química, Universidade Estadual do Oeste do Paraná).

Schmitz, A. C. (2018). Elaboração e caracterização de extratos vegetais hidrossolúveis de castanha de caju e de baru. (Bacharelado em Engenharia de Alimentos, Universidade Federal da Fronteira Sul).

Sharma, G., Sharma, S., Kumar, A., Naushad, M., Du, B., Ahamad, T., \& Stadler, F. J. (2019). Honeycomb structured activated carbon synthesized from Pinus roxburghii cone as effective bioadsorbent for toxic malachite green dye. Journal of Water Process Engineering, 32, 100931.

Silva, E. C. (2015). Remoção de azo-corantes de efluente aquoso modelo por adsorção em carvão ativado. (Doutorado em Engenharia Química, Universidade Federal de Pernambuco).

Silva, J. G. S., Junior, R. S. M., \& Lobato, A. K. D. C. L. (2020). Coagulantes Naturais Utilizados no Tratamento de Efluentes em Indústrias Têxteis. Cadernos de Prospecção, 13(5), 1450.

Souza, T. N. V., de Carvalho, S. M. L., Vieira, M. G. A., da Silva, M. G. C., \& Brasil, D. D. S. B. (2018). Adsorption of basic dyes onto activated carbon: experimental and theoretical investigation of chemical reactivity of basic dyes using DFT-based descriptors. Applied Surface Science, $448,662-670$.

Souza, T. N. V., Vieira, M. G. A., da Silva, M. G. C., Brasil, D. D. S. B., \& de Carvalho, S. M. L. (2019). H 3 PO 4-activated carbons produced from açai stones and Brazil nut shells: removal of basic blue 26 dye from aqueous solutions by adsorption. Environmental Science and Pollution Research, 26 (28), $28533-28547$.

Spagnoli, A. A, Giannakoudakis, D. A, \& Bashkova, S. (2017). Adsorption of methylene blue on cashew nut shell based carbons activated with zinc chloride: The role of surface and structural parameters. Journal of Molecular Liquids, 229, 465-471.

Takeshita, V., Mendes, K. F., Pimpinato, R. F., \& Tornisielo, V. L. (2020). Adsorption isotherms of diuron and hexazinone in drinking water using four agroindustrial residues. Planta Daninha, 38.

Tang, S. H., \& Zaini, M. A. A. (2020). Development of activated carbon pellets using a facile low-cost binder for effective malachite green dye removal. Journal of Cleaner Production, 253, 119970.

Tavares, P. T. (2016). Caracterizações física e química de resíduos sólidos da cajucultura e avaliação do potencial energético em processos de conversão térmica. (Mestrado em Energias Renováveis, Universidade Federal da Paraíba). 
Research, Society and Development, v. 10, n. 3, 21710313221, 2021

(CC BY 4.0) | ISSN 2525-3409 | DOI: http://dx.doi.org/10.33448/rsd-v10i3.13221

Tkaczyk, A., Mitrowska, K., \& Posyniak, A. (2020). Synthetic organic dyes as contaminants of the aquatic environment and their implications for ecosystems: a review. Science of The Total Environment, 717, 137222.

Toor, M., \& Jin, B. (2012). Adsorption characteristics, isotherm, kinetics, and diffusion of modified natural bentonite for removing diazo dye. Chemical Engineering Journal, 187, 79-88.

Trazzi, P. A., Higa, A. R., Dieckow, J., Mangrich, A. S., \& Higa, R. C. V. (2018). Biocarvão: realidade e potencial de uso no meio florestal. Ciência Florestal, 28(2), 875-887.

Uchôa, L. Y. K. D. S. (2019). Estudo da Cinética de Adsorção do Corante Maxilon Blue por Quitina Sintetizada a partir da Casca de Camarão (Bachelor's thesis, Universidade Federal do Rio Grande do Norte).

Vasques, A. R., Souza, S., Weissenberg, L., Souza, A. A. U. D., \& Valle, J. A. B. (2011). Adsorção dos corantes RO16, RR2 e RR141 utilizando lodo residual da indústria têxtil. Engenharia Sanitaria e Ambiental, 16(3), 245-252.

Venkataraghavan, R., Thiruchelvi, R., \& Sharmila, D. (2020). Statistical optimization of textile dye effluent adsorption by Gracilaria edulis using PlackettBurman design and response surface methodology. Heliyon, 6(10), e05219.

Yu, Y., Qiao, N., Wang, D., Zhu, Q., Fu, F., Cao, R., \& Xu, B. (2019). Fluffy honeycomb-like activated carbon from popcorn with high surface area and welldeveloped porosity for ultra-high efficiency adsorption of organic dyes. Bioresource technology, 285, 121340.

Zhang, H., Gu, L., Zhang, L., Zheng, S., Wan, H., Sun, J., \& Xu, Z. (2017). Removal of aqueous Pb (II) by adsorption on Al2O3-pillared layered MnO2. Applied Surface Science, 406, 330-338. 